\author{
Universidade de $\mathbf{S} \tilde{a}$ O Paulo \\ F aculdade de Medicina de Ribeirão Preto
}

ANA PAULA CASSIANO SILVEIRA

Efeitos do azul de metileno na lesão pulmonar aguda induzida por ácido oleico em ratos

RIBEIRÃO PRETO 


\section{Efeitos do azul de metileno na lesão pulmonar aguda induzida por ácido oleico em ratos}

Dissertação apresentada à Faculdade de Medicina de Ribeirão Preto da Universidade de São Paulo junto ao Departamento de Clínica Cirúrgica, para obtenção do título de Mestre em Ciências Médicas.

Área de Concentração: Clínica Cirúrgica

Opção: Morfologia e Medicina Experimental

Orientador: Prof. Dr. Paulo Roberto Barbosa Evora

Co-orientadora: Profa. Dra. Andrea Carla Celotto

\section{RIBEIRÃO PRETO}




\begin{abstract}
AUTORIZO A REPRODUÇÃO E DIVULGAÇÃO TOTAL OU PARCIAL DESTE TRABALHO, POR QUALQUER MEIO CONVENCIONAL OU ELETRÔNICO, PARA FINS DE ESTUDO E PESQUISA, DESDE QUE CITADA A FONTE.
\end{abstract}

Catalogação na Publicação

Serviço de Documentação

Faculdade de Medicina da Universidade de São Paulo

Silveira, Ana Paula Cassiano

Efeitos do azul de metileno na lesão pulmonar aguda induzida por ácido oleico em ratos/ Ana Paula Cassiano Silveira; orientador Paulo Roberto Barbosa Evora; Coorientadora Andrea Carla Celotto. - Ribeirão Preto, 2014.

$59 \mathrm{p}$.

Dissertação (Mestrado - Programa de Pós-Graduação em Ciências Médicas. Área de Concentração: Clínica Cirúrgica) - Faculdade de Medicina de Ribeirão Preto da Universidade de São Paulo.

1. Lesão Pulmonar Aguda. 2. Azul de Metileno 3. Ácido Oleico 4. Guanilato Ciclase Solúvel 


\section{FOLHA DE APROVAÇÃO}

Ana Paula Cassiano Silveira

Efeitos do azul de metileno na lesão pulmonar aguda induzida por ácido oleico em ratos

Dissertação apresentada à Faculdade de Medicina de Ribeirão Preto da Universidade de São Paulo junto ao Departamento de Clínica Cirúrgica, para obtenção do título de Mestre em Ciências Médicas.

Área de Concentração: Clínica Cirúrgica

Aprovado em:

Banca Examinadora:

$\operatorname{Prof}(\mathrm{a}) \cdot \operatorname{Dr}(\mathrm{a})$

Instituição: Assinatura:

$\operatorname{Prof}(a) \cdot \operatorname{Dr}(a)$

Instituição: Assinatura:

$\operatorname{Prof}(a) \cdot \operatorname{Dr}(a)$

Instituição: Assinatura: 
Dedico, com todo meu carinho e admiração, ao meu mestre e orientador Paulo Evora, sem a qual esse trabalho seria apenas uma ideia.

Obrigada pelo cuidado e persistência ao desenrolar desses anos de pesquisa e por você acreditar que isso seria possível. 


\section{AGRADECSO...}

A Deus que, pelo seu infinito amor, mandou seu filho Jesus em sacrifício e redenção e que por sua imensa graça nos conduz a salvação eterna. "A nosso Deus e Pai seja dada glória pelos séculos dos séculos" Filipenses 4.20.

Aos meus pais, Ana Maria e Paulo Braga, que me ensinaram "o caminho onde eu deveria andar”. Vocês são responsáveis pelo meu caráter e pela minha educação. Esse trabalho é resultado do esforço de vocês quando, no tempo certo, me conduziram pela mão.

Ao meu irmão Fernando, minha eterna admiração por sua competência em tudo o que faz. Companheiro de república participou da melhor fase da minha vida. Obrigada pela companhia em Ribeirão Preto, e por fazer os dias aqui serem vividos no aconchego da família.

A minha irmã Cacau, minha eterna "Concheta". Mesmo alienada de tudo o que acontece no mundo, sempre ocupa um lugar imenso no meu coração. Nossa família é o combustível que motiva minhas conquistas.

Ao Ziotti, namorado, amigo e companheiro de todos os dias. Bunito, você apareceu na fase mais difícil desse trabalho. Seu senso de humor, seu amor, sua paciência, seu cuidado e sua ajuda foram fundamentais para que eu conseguisse passar por esse momento. Agradeço a Deus por Ele ter colocado você no meu caminho. Aprendo um pouco mais a cada dia com você. Te amo. (PS: Coelho!)

A minha cunhada, amiga e irmã, Greice. Presente de Deus para a nossa família. Obrigada pelo incentivo, orações e cuidado que sempre demonstrou por mim.

Ao Roque, por sua amizade e carinho, e por cuidar da minha mãe. Assim, consigo ficar distante sabendo que ela está em boa companhia.

A minha sogra Adriana, ao meu sogro Sidnei e as minhas cunhadas Fernanda e Isabela, obrigada por me acolherem e por dividirem comigo esse filho e esse irmão tão 
especial que vocês têm, e por podermos dividir essa conquista juntos.

A minha irmã de coração, Lidi, companheira em todos os momentos, exemplo de dedicação e competência como pós-graduanda. Minha "mestra e orientadora", obrigada pela paciência. Te amo amiga, sem você aqui nada teria a mesma graça.

A Tia Lidia, minha segunda mãe, por todas as vezes que se preocupou e cuidou de mim quando tudo em casa estava a maior bagunça! Sua companhia, seu carinho e nossas conversas sempre foram um incentivo para continuar batalhando.

A minha técnica de laboratório preferida, Agnes. Sem você nada disso teria sido possível. Serei eternamente grata a você pelo apoio, dedicação e consolo nas dificuldades. Mas principalmente obrigada pela sua calma, pela companhia e alegria todos os dias, mesmo quando "a casa estava caindo".

Aos meus orientadores, Paulo Evora e Carla, muito obrigada pela dedicação, pela troca de experiência, por todo ensinamento dispensado e pela persistência em busca de respostas. Aprendi a fazer a verdadeira pesquisa com vocês. Deixo a minha admiração pelos pesquisadores que são.

A Professora Simone, meus sinceros agradecimentos pelo tempo dispensado, pelos ensinamentos e pelo cuidado em todas as observações feitas. Meu desejo é que Deus continue abençoando a sua vida e a sua recuperação para que você continue realizando o seu trabalho dessa forma tão brilhante. Muito obrigada.

A Dani Vento, companheira fiel nessa batalha. Ao seu lado ri, chorei, perdi as esperanças e recuperei-as de novo. Obrigada por não me deixar desistir... e por não desistir junto comigo! Valeu a pena todas as risadas ao seu lado.

A todos os amigos do Laboratório de Função Endotelial, nossa "Tropa de Elite": Luciana Garros, Agnes, Marco Túlio, Tales, Verena, Carla, Débora e Ariadne; e aos amigos agregados Rodrigo Galindo e Lívia. Muito obrigada pela ajuda e pela companhia de todos.

A todas as pessoas que torceram e participaram de muitos momentos ao longo dessa 
caminhada, em especial aos meus grandes e queridos amigos: Purga, Bando, Baby, Dako, Toisso, Gambá, Fernanda, Deborah, Alessa, Gra, Pri e Anderson;e as minhas primas, Ni e Kika, que mesmo à distância nunca deixaram de orar, torcer e se orgulhar.

Aos meus amigos Patrícia, Iara, Evelyn, Karla, Paulo, Marina e Joana pela companhia de todos os dias no trabalho e na "salinha", e por participarem e torcerem pela obtenção desse título. Em especial agradeço a Márcia por todas as trocas de horário, pelo apoio e pelo incentivo sempre acreditando que no fim "tudo iria dar certo"; e a Rita, irmã mais velha, sem palavras para demonstrar o meu amor e gratidão por cada dia ao seu lado.

A minha "ex-chefe" e amiga Viviane, e a minha chefe Amira, por colaborarem sempre que necessário para que os meus horários permitissem a conclusão dessa pesquisa.

Aos amigos do Laboratório de Histologia, Sandra e Jorge, pelo trabalho em equipe, pelo carinho e prontidão em nos ajudar.

As técnicas do Laboratório de Bioquímica e Transplante Hepático, Maria Cecília, Clarisse, Maria Elisa e Maria Aparecida, pelas análises bioquímicas e pela disposição em ajudar sempre que necessário.

Aos funcionários da Cirurgia Experimental, pela ajuda e por ensinar as técnicas cirúrgicas.

As secretárias do Departamento de Cirurgia e Anatomia, Juliana, Camila e Larissa, pelo cuidado e incentivo.

A toda equipe do laboratório do Prof. Fernando Cunha, em especial Jozi e Dani Nascimento. Obrigada pela colaboração.

À Faculdade de Medicina de Ribeirão Preto da Universidade de São Paulo, pelas portas abertas; e ao Conselho Nacional de Desenvolvimento Científico e Tecnológico $(\mathrm{CNP} q)$ pelo apoio financeiro através do Projeto Universal.

E aos animais que cederam suas vidas para que eu pudesse concluir este trabalho. 
"Sendo assim, as revoluções não concernem a pequenas questões, mas nascem de pequenas questões e põem em jogo grandes questões.” Aristóteles 


\section{RESUMO}

SILVEIRA, A. P. C. Efeitos do azul de metileno na lesão pulmonar aguda induzida por ácido oleico em ratos. 2014. Dissertação (Mestrado) - Faculdade de Medicina de Ribeirão Preto, Universidade de São Paulo, Brasil.

INTRODUÇÃO. O termo Lesão Pulmonar Aguda (LPA) é usado para descrever a resposta pulmonar à lesão que ocorre diretamente ou indiretamente nos pulmões. A quebra da barreira alvéolo-capilar determina o influxo de líquido rico em proteínas para dentro dos espaços alveolares, sendo necessária a reabsorção desse líquido no processo de resolução da LPA. A infusão intravenosa de Ácido Oleico (AO) em ratos provoca agudamente edema alveolar difuso e focos hemorrágicos intra-alveolares, sendo um bom modelo de indução. Estudos relatam que o Azul de Metileno (AM) atenua tais lesões, com efeito protetor, no tecido pulmonar, e reduz o edema presente na LPA em animais com sepse através da inibição da guanilato ciclase solúvel (GCs), uma enzima ativadora da via NO-GMPc.

OBJETIVO. Estudar a repercussão da inibição da GCs pelo AM na permeabilidade capilar pulmonar ministrando-o antes e após a indução da lesão pulmonar por AO.

MÉTODO. Ratos Wistar foram divididos em 5 grupos: Sham com infusão de salina em bolus; $A M$ com infusão de $\mathrm{AM}$ por $2 \mathrm{~h}$; $A O$ com infusão de $\mathrm{AO}$ em bolus, $A M / A O$ com infusão de AM por 2h, sendo que, após 5 min do início, recebeu AO simultaneamente em bolus e $A O / A M$ com infusão de $\mathrm{AO}$ em bolus e, após $2 \mathrm{~h}$, infusão de $\mathrm{AM}$ por mais $2 \mathrm{~h}$. Após $4 \mathrm{~h}$ foi realizada a coleta de materiais (sangue, lavado bronco-alveolar e tecido pulmonar) para análise do NO plasmático e tecidual, gasometria arterial, cálculo do peso úmido/peso seco (PU/PS) e histologia do tecido pulmonar de todos os grupos. A estatística utilizada foi a análise de variância (one-way ANOVA) com p<0.05.

RESULTADO. Não foi encontrado hipoxemia grave após 4h de lesão. O grupo AO apresenta um aumento no número de proteínas no lavado bronco-alveolar e na relação PU/PS comparado aos grupos controle: Sham e AM, confirmando a presença de lesão e alteração de permeabilidade pulmonar. Os grupos tratados com AM apresentaram melhora na permeabilidade pulmonar, porém, apenas o grupo pré-tratamento (AM/AO) apresentou diferença estatística na redução do extravasamento de proteínas no lavado. Não foram encontradas diferenças significativas no NO plasmático e tecidual. Na microscopia, a congestão capilar foi intensa, acompanhada de múltiplos focos de edema alveolar, exsudato intra-alveolar proteico, áreas de hemorragia e infiltrado inflamatório neutrofílico, tanto no 
interstício quanto nos septos alveolares.Os grupos tratados com AM apresentaram diminuição das áreas de edema, exsudação e hemorragia, porém, com maior evidência no grupo AM/AO.

CONCLUSÃO. O AM diminui a permeabilidade pulmonar quando administrado de maneira precoce amenizando os danos causados pela LPA induzida por AO.

Palavras-Chave: Lesão Pulmonar Aguda; Azul de Metileno, Ácido Oleico, Guanilato Ciclase Solúvel. 


\begin{abstract}
Silveira, APC Effects of methylene blue in acute lung injury induced by oleic acid in rats. 2014. Master (Dissertation) - Faculty of Medicine of Ribeirão Preto, University of São Paulo, Brazil.
\end{abstract}

BACKGROUND. The term Acute Lung Injury (ALI) is used to describe the response to lung injury that occurs directly or indirectly in the lungs. The rupture of the alveolar capillary barrier determines the influx of protein-rich fluid into the alveolar spaces, the reabsorption of this fluid in the process of resolving the ALI is required. Intravenous infusion of oleic acid (OA) in rats acutely causes diffuse alveolar edema and intra-alveolar hemorrhagic foci, being a good role model induction. Studies have reported that Methylene Blue (MB) attenuates such injuries, with a protective effect in lung tissue and reduce edema present in the ALI present in with sepsis by inhibition of soluble guanylate cyclase (sGC), an activator of the enzyme NO- cGMP pathway.

OBJECTIVE. To study the effect of inhibition of sGC by MB in pulmonary capillary permeability ministering to the before and after induction of lung injury by OA.

METHOD. Wistar rats were divided into 5 groups: Sham infused with saline bolus, $M B$ infused with $\mathrm{MB}$ for $2 \mathrm{hrs}, O A$ infused with $\mathrm{OA}$ bolus, $M B / O A$ infused with $\mathrm{MB}$ for $2 \mathrm{hrs}$, and after $5 \mathrm{~min}$ from the beginning, simultaneously received $\mathrm{OA}$ bolus and $O A / M B$ infused with OA bolus and after $2 \mathrm{hrs}, \mathrm{MB}$ infusion for $2 \mathrm{hrs}$. After $4 \mathrm{hrs}$ the collection of materials was performed (blood, bronchoalveolar lavage and lung tissue) for analysis of plasma and tissue NO, arterial blood gases, calculation of the wet weight/dry weight (WW/DW) and histology of lung tissue from all groups. The statistic used was analysis of variance (one-way ANOVA) with $\mathrm{p}<0.05$.

RESULTS. Not found severe hypoxemia after $4 \mathrm{hrs}$ of injury. The OA group shows an increase in the number of proteins in bronchoalveolar lavage and in WW/DW ratio compared to the control groups: Sham and MB, confirming the presence of injury and alterations of lung permeability. The groups treated with MB showed improvement in lung permeability, however, only the pretreatment group (MB/OA) showed statistical significance in reducing the leakage of protein in the lavage. No significant differences were found in plasma and tissue NO. In microscopy, capillary congestion was intense, accompanied by multiple foci of alveolar edema, intra-alveolar proteinaceous exudates, areas of hemorrhage and neutrophilic inflammatory infiltrate in both the interstitium and in the alveolar septa. The groups treated 
with MB showed reduction in areas of edema, exudation and hemorrhage, however, most obviously in MB/OA group.

CONCLUSION. The MB decreases lung permeability when administered as early as possible, mitigating the damage caused by OA-induced ALI.

Keywords: Acute lung injury, methylene blue, oleic acid, soluble guanylate cyclase 


\section{LISTA DE FIGURAS}

Figura 1 Estrutura molecular do Azul de Metileno. Reproduzido a partir de He \& Tebo, 1998.

Figura 2 Mecanismo de relaxamento da célula muscular lisa vascular mediado pelo óxido nítrico. Reproduzido a partir de Baldo, 2009. 28

Figura 3 Esquema experimental 32

Figura 4. Imagem do processo de canulação da artéria femoral para coleta de sangue e infusão de drogas. 33

Figura 5. Método de coleta do lavado bronco-alveolar 34

Figura 6. Lobo pulmonar direito (A- superior, B- médio e C-inferior). 35

Figura 7. Relação $\mathrm{PaO} 2 / \mathrm{FiO} 2$ com $\mathrm{FiO} 2$ de $21 \%$. 37

Figura 8. Dosagem de proteínas totais no lavado bronco-alveolar. 38

Figura 9. Relação PU/PS dos pulmões 38

Figura 10. Análise do NOx plasmático e tecidual. 39

Figura 11. Imagem macroscópica do tecido pulmonar. 40

Fig. 12. Alterações microscópicas observadas nos pulmões após infusão de Ácido Oleico.

Fig. 13. Imagem panorâmica dos pulmões comparando os grupos analisados 42 


\section{LISTA DE ABREVIATURAS E SIGLA}

AM

AM/AO

AO

AO/AM

$\mathrm{CO}_{2}$

EG

eNOS

GCs

GMPc

i.p.

i.v.

IFN- $\gamma$

IL-1

iNOS

LPA

LPS

nNOS

NO

$\mathrm{NO}^{2-}$

NO $^{3-}$

NOS

NOx

$\mathbf{O}_{2}$

$\mathrm{PaO}_{2} / \mathrm{FiO}_{2}$

PU/PS

SDRA

TNF- $\alpha$
Azul de Metileno

Azul de Metileno / Ácido Oleico

Ácido Oleico

Ácido Oleico / Azul de Metileno

Gás Carbônico

Embolia Gordurosa

Isoforma da NOS endotelial

Guanilato Ciclase Solúvel

Guanosina Monofosfato Cíclica

Infusão intraperitonial

Infusão intravenosa

Interferon $\gamma$

Interleucina-1

Isoforma da NOS induzida

Lesão Pulmonar Aguda

Endotoxina Lipopolissacarideo

Isoforma da NOS neuronal

Óxido Nítrico

Nitrito

Nitrato

Óxido Nítrico Sintase

Dosagem de nitrito /nitrato plasmático e tecidual

Oxigênio

Relação da pressão parcial de $\mathrm{O}_{2}$ pela fração inspirada de $\mathrm{O}_{2}$ Peso úmido / Peso seco

Síndrome do Desconforto Respiratório Agudo

Fator de necrose tumoral $\alpha$ 


\section{SUMÁRIO}

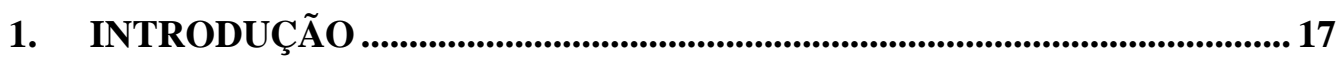

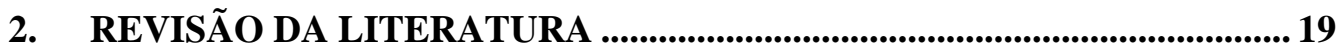

2.1. Anatomia funcional da circulação pulmonar .............................................. 19

2.1.1. Circulação Pulmonar ......................................................................19

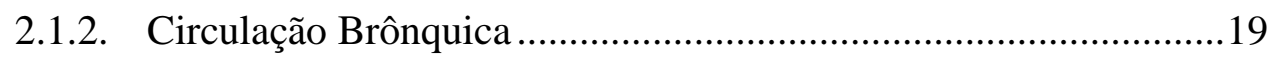

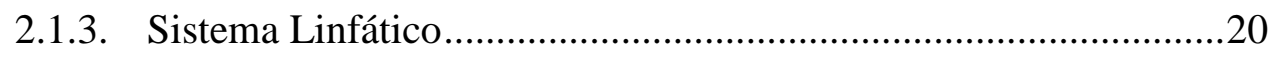

2.2. Transporte de líquidos e de solutos nos pulmões ...................................... 20

2.3. Lesão Pulmonar Aguda (LPA) _.............................................................. 21

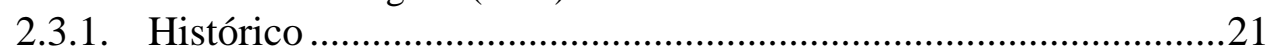

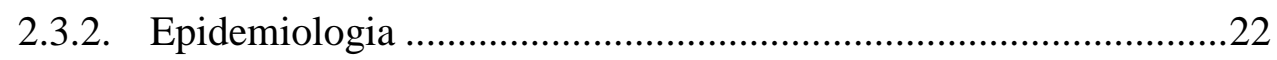

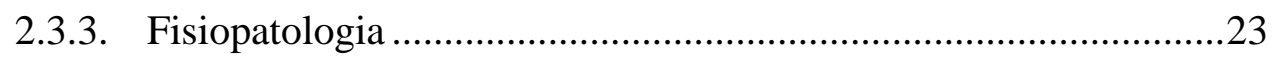

2.3.4. Edema Pulmonar .....................................................................24

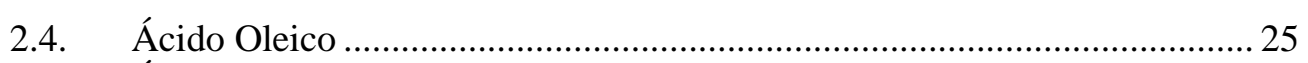

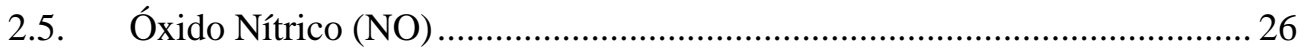

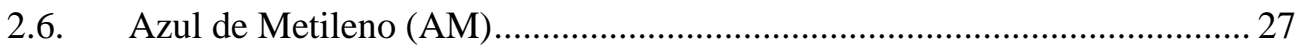

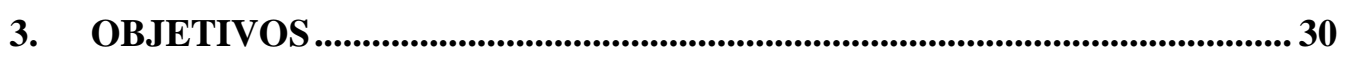

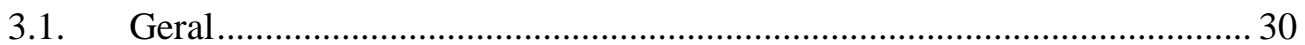

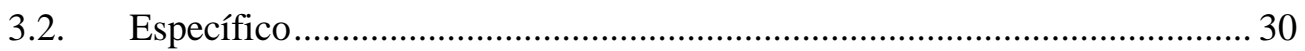

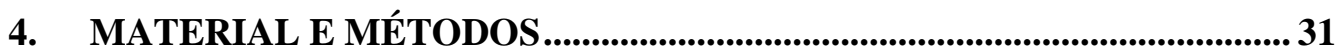

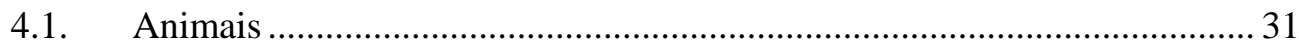

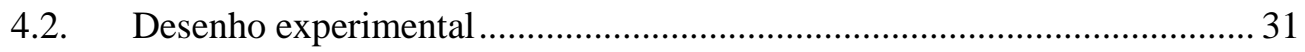

4.3. Indução da lesão pulmonar aguda ............................................................ 32

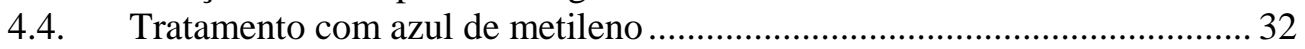

4.5. Técnica anestésica e operatória .................................................................... 32

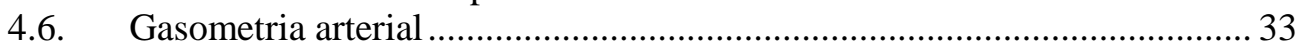

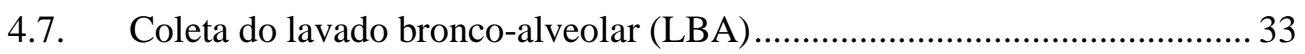

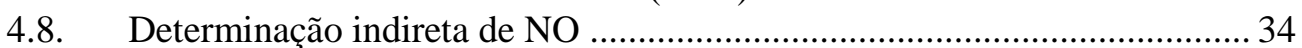

4.9. Análise da relação peso úmido/peso seco (PU/PS) do pulmão ..................... 34

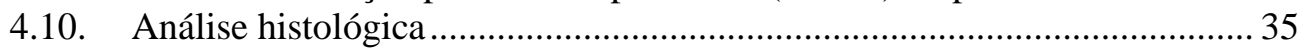

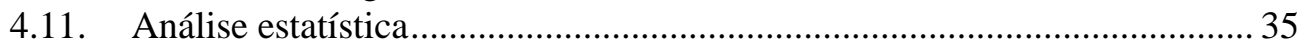

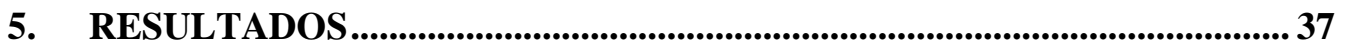

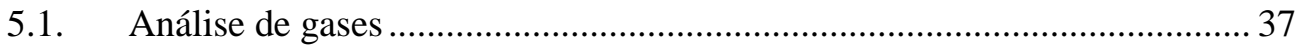

5.2. Alteração da permeabilidade pulmonar....................................................... 37

5.3. Nitrito/Nitrato (NOx) plasmático e tecidual.................................................. 38

5.4. Análise macroscópica e microscópica do tecido pulmonar........................... 39

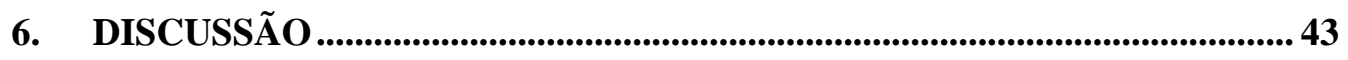

6.1. Método de indução da LPA por AO........................................................... 43 


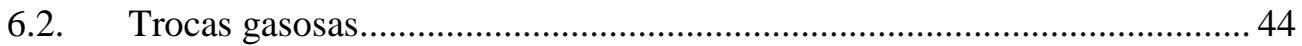

6.3. Permeabilidade capilar pulmonar.............................................................. 45

6.4. Nitrito/Nitrato (NOx) plasmático e tecidual.................................................. 46

6.5. Achados macroscópicos e histológicos ........................................................ 48

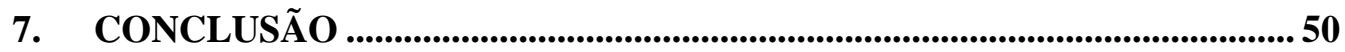

REFERÊNCIAS BIBLIOGRÁFICAS.........................................................5 51

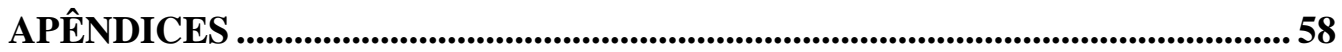

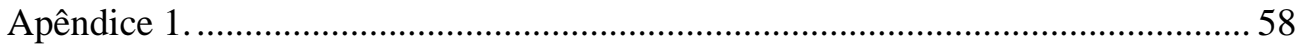

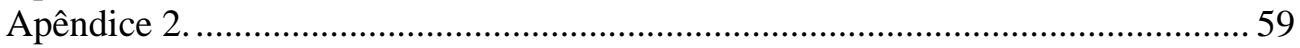

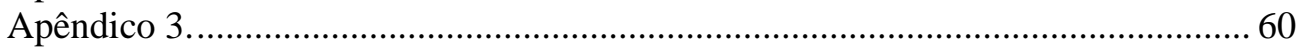




\section{INTRODUÇÃO}

Sob condições fisiológicas, o endotélio pulmonar forma uma barreira semipermeável a partir do tecido circundante que controla a dinâmica da troca de fluídos e de macromoléculas entre o sangue e o interstício (TOYA e MALIK, 2012).

Esta permeabilidade endotelial desempenha um papel crucial na regulação da homeostase normal do tecido e na manutenção da função pulmonar (DULUC e WOJCIAKSTOTHARD, 2014) .

A Lesão Pulmonar Aguda (LPA) é uma síndrome inflamatória onde ocorre o comprometimento da barreira endotelial vascular, principalmente nas vênulas pós-capilares, levando a um aumento da permeabilidade associado a uma ampla anormalidade clínica radiológica e fisiológica (BERNARD, 2005). Essa alteração de permeabilidade vascular provoca o extravazamento de líquidos rico em proteínas nos tecidos pulmonares, podendo evoluir com atelectasias, hipoxemia e insuficiência respiratória. (VOELKEL e ROUNDS, 2009).

O grau de aumento da permeabilidade vascular pulmonar correlaciona-se clinicamente com a gravidade da lesão pulmonar e com a quantidade de tráfego de neutrófilos no pulmão lesado. Caso esse aumento persista contribuirá para a alta morbidade e mortalidade de pacientes com LPA (VOELKEL e ROUNDS, 2009).

A indução da LPA nos modelos experimentais, em coelhos e ratos, pode ser feita pela administração de ácido oleico (AO) (ZHU et al., 1998; KUWABARA et al., 2001; BOUMGARTEN, DALMARCO e GUIMARÃES, 2008; CHEN et al., 2008; GRIGORIU, BALAN e RUSU, 2008; BAO et al., 2010). Teoricamente, o modelo com AO induz uma lesão pulmonar por mecanismo direto causado por embolia gordurosa (EG), provocando edema pulmonar de origem não-cardiogênica (VOLPE, LIN e THRALL, 1994; QUELUZ, DEFAVERI e EL--FAKHOURI, 1997). Porém, estudos recentes apontam a influência dos neutrófilos na gênese dessas lesões (FILOMENO et al., 2005).

Esses modelos podem ainda apresentar um aumento da produção de óxido nítrico (NO) (CHEN et al., 2000; CHEN et al., 2008; YEH et al., 2008), assim como lesão pulmonar inflamatória, alteração de permeabilidade capilar e edema pulmonar (VOLPE, LIN e THRALL, 1994; BRAUER et al., 2000; KUWABARA et al., 2001; HALL et al., 2006; RITTER et al., 2006).

O NO é um potente vasodilatador e seu envolvimento na resposta inflamatória pode 
ter relação com sua habilidade em aumentar a permeabilidade vascular e o edema através de mudanças no fluxo sanguíneo local e do aumento na produção de prostaglandinas próinflamatórias (CERQUEIRA e YOSHIDA, 2002), características estas presentes na LPA.

O azul de metileno (AM) ou cloreto de metiltioninium é um corante derivado das tiazidas (C16H18CIN3S, 3H2O) quimicamente conhecido como cloreto de 3,7 Bis-dimetilamino fenazationium tri-hidratado (EVORA, CELOTTO e CAPELLINI, 2011). Seus possíveis efeitos terapêuticos dão-se principalmente pela sua interação com a via NO/GMPc (guanosina monofosfato cíclica), inibindo a ação da enzima guanilato ciclase solúvel (GCs) (EVGENOV， SAGER e BJERTNAES， 2001; EVGENOV， SVEINBJORNSSON e BJERTNAES, 2001; FERNANDES, 2006).

Estudos relatam que o AM atenua as lesões presente na LPA em animais com sepse através da inibição da enzima GCs, promovendo, assim, um efeito protetor, com redução do edema pulmonar (EVGENOV, SAGER e BJERTNAES, 2001; EVGENOV et al., 2002; KIROV, EVGENOV e BJERTNAES, 2003; DIAZ, 2009).

A presente investigação foi planejada com a finalidade de ampliar os conhecimentos sobre a possível repercussão da inibição da GCs pelo AM na permeabilidade capilar pulmonar através de sua ação na via NO/GMPc . O objetivo maior foi verificar o efeito do AM como profilaxia e como tratamento do edema pulmonar presente na LPA, administrando-o antes e após a indução da lesão pulmonar por AO. 


\section{REVISÃO DA LITERATURA}

\subsection{Anatomia funcional da circulação pulmonar}

A irrigação vascular dos pulmões é composta pela circulação pulmonar e brônquica (SCANLAN, WILKINS e STOLLER, 2000; LEVITZKY, 2009).

Os vasos sanguíneos pulmonares formam uma série de tubos que se ramificam, desde a artéria pulmonar aos capilares, e, de volta, às veias pulmonares.

Inicialmente, as artérias, veias e brônquios seguem trajetos próximos entre si, porém, em direção à periferia do pulmão as veias se afastam dos brônquios e das artérias concentrando-se mais entre os lóbulos pulmonares. Os capilares formam uma densa rede nas paredes dos alvéolos (WEST, 1990).

\subsubsection{Circulação Pulmonar}

A circulação pulmonar se origina do lado direito do coração. É responsável pelo transporte do sangue venoso misto dos tecidos através dos pulmões para restaurar o seu conteúdo de oxigênio $\left(\mathrm{O}_{2}\right)$ e remover o dióxido de carbono $\left(\mathrm{CO}_{2}\right)$. O sangue venoso misto pobremente oxigenado é liberado aos pulmões através da artéria pulmonar, que se subdividem em arteríolas pulmonares e capilares alveolares, nas unidades pulmonares terminais. Os capilares alveolares fornecem uma grande área de superfície para o intercâmbio de $\mathrm{O}_{2}$ e $\mathrm{CO}_{2}$ com os alvéolos (SCANLAN, WILKINS e STOLLER, 2000; LEVITZKY, 2009).

As paredes finas e a pequena quantidade de músculo liso encontrado nas artérias pulmonares comportam importantes consequências fisiológicas. Os vasos pulmonares oferecem muito menos resistência ao fluxo sanguíneo que os vasos arteriais sistêmicos, sendo também muito mais distensíveis e compressíveis (LEVITZKY, 2009).

Essa baixa resistência implica em uma pressão circulatória pulmonar em média um sexto da circulação sistêmica, apesar de comportar todo débito cardíaco. Essas pressões baixas são essenciais na manutenção do equilíbrio líquido na interface alvéolo-capilar (WEST,1990; SCANLAN, WILKINS e STOLLER, 2000).

\subsubsection{Circulação Brônquica}

As artérias brônquicas têm origens variáveis, seja diretamente na aorta, seja nas artérias intercostais. Elas fornecem sangue arterial para a árvore traqueobrônquica e para outras estruturas do pulmão até o nível dos bronquíolos terminais (WEST, 1990; LEVITZKY, 2009). Proporcionam também fluxo sanguíneo aos linfonodos hilares, à pleura visceral, às 
artérias e veias pulmonares, aos nervos vagos e ao esôfago (SCANLAN, WILKINS e STOLLER, 2000).

O sangue venoso misto nas artérias pulmonares não possui oxigênio suficiente para as necessidades metabólicas do pulmão, sendo necessário um suprimento arterial separado que também acompanha o brônquio (SCANLAN, WILKINS e STOLLER, 2000).

As estruturas pulmonares distais aos bronquíolos terminais, os bronquíolos respiratórios, os ductos alveolares, os sacos alveolares e os alvéolos recebem oxigênio diretamente por difusão a partir do ar alveolar e nutrientes a partir do sangue venoso misto existente na circulação pulmonar (LEVITZKY, 2009).

\subsubsection{Sistema Linfático}

O sistema linfático pulmonar é composto por vasos superficiais e profundos. A rede superficial (pleural) drena a superfície pulmonar e a pleura e a rede profunda (peribroncovascular) drena o tecido pulmonar. Os vasos linfáticos profundos estão intimamente associados com as unidades pulmonares terminais, porém, não se estendem até o nível da membrana alvéolo-capilar (SCANLAN, WILKINS e STOLLER, 2000).

Sua função principal é eliminar o líquido dos espaços intersticiais. Também possui um papel importante no sistema imunológico, removendo bactérias, corpos estranhos e resíduos celulares através da linfa. O sistema linfático trabalha com células fagocitárias nos alvéolos para defesa contra agentes estranhos capazes de penetrar em nível alveolar (SCANLAN, WILKINS e STOLLER, 2000; BERTONI, 2012).

$\mathrm{O}$ edema pulmonar e o derrame pleural se tornam evidentes quando o sistema linfático é incapaz de remover o excesso de líquido dos pulmões (SCANLAN, WILKINS e STOLLER, 2000; LEVITZKY, 2009).

\subsection{Transporte de líquidos e de solutos nos pulmões}

O espaço intersticial é o espaço existente entre o epitélio alveolar e os capilares. É uma região muito estreita que permite a difusão dos gases entre o sangue capilar e o ar alveolar (CAPELOZZI, 1998).

O interstício do lado não alveolar dos capilares possui uma matriz menos densa constituída por fibroblastos, tecido conjuntivo colagenoso, elastina e mucopolissacarídeos num gel de ácido hialurônico. As propriedades físicas dessa matriz permitem a absorção de água sem aumentar a pressão hidrostática no interior do espaço intersticial e sem afetar o intercâmbio gasoso pulmonar (SCANLAN, WILKINS e STOLLER, 2000). 
Os capilares alveolares possuem uma propriedade seletiva às proteínas e, consequentemente, elas extravazam. Essa propriedade permite o movimento de soluto dos espaços intravasculares para o interstício pulmonar (SCANLAN, WILKINS e STOLLER, 2000; TOYA e MALIK, 2012).

A taxa de intercâmbio de líquidos entre o espaço intravascular e o interstício pulmonar é determinada pelas influências combinadas de forças hidrostáticas e osmóticas. A relação entre essas duas forças é descrita pela equação de Starling:

$\mathrm{Q}_{\mathrm{f}}=\mathrm{K}_{\mathrm{f}}\left[\left(\mathrm{P}_{\mathrm{c}}-\mathrm{P}_{\mathrm{is}}\right)-\sigma\left(\pi_{\mathrm{pl}}-\mu_{\mathrm{is}}\right)\right]$

Onde: $\mathrm{Q}_{\mathrm{f}}=$ fluxo total de líquido

$\mathrm{K}_{\mathrm{f}}=$ coeficiente de filtração capilar; este descreve as características de permeabilidade da membrana aos fluidos

$\mathrm{P}_{\mathrm{c}}=$ pressão hidrostática capilar

$\mathrm{P}_{\text {is }}=$ pressão hidrostática no liquido intersticial

$\sigma=$ coeficiente de reflexão; este descreve a capacidade da membrana de prevenir o extravasamento das partículas do soluto

$\pi_{\mathrm{pl}}=$ pressão coloidosmótica (oncótica) do plasma

$\mu_{\text {is }}=$ pressão coloidosmótica do liquido intersticial

A equação de Starling é extremamente útil para compreendermos as possíveis causas do edema pulmonar, apesar de somente a pressão coloidosmótica do plasma $\left(\pi_{\mathrm{pl}}\right)$ poder ser medida clinicamente (WEST, 1990; SCANLAN, WILKINS e STOLLER, 2000; LEVITZKY, 2009).

\subsection{Lesão Pulmonar Aguda (LPA)}

\subsubsection{Histórico}

A primeira descrição científica de edema pulmonar de origem não-cardiogênica data de 1821 quando Laennec descreveu essa patologia no livro "A Treatise on Diseases of the Chest" e a denominou como anasarca idiopática dos pulmões. Na década de 1950, o termo "edema pulmonar" foi introduzido na Medicina pela Biblioteca Nacional de Medicina. Entretanto, não foi feita nenhuma distinção entre as origens cardiogênica e não-cardiogênica (BERNARD, 2005).

De acordo com Bernard (2005), a primeira caracterização da patologia foi feita em 1967 quando Ashbaugh e colaboradores descreveram a Síndrome do Desconforto Respiratório do Adulto na qual os pacientes apresentavam infiltrado pulmonar difuso bilateral 
e necessitavam de ventilação mecânica com altos níveis pressóricos. A mesma poderia ser desencadeada por uma ampla gama de insultos como aspiração de conteúdo gástrico, sepse, trauma, entre outros.

No entanto, somente em 1992 o Consenso Americano-Europeu desenvolveu e padronizou uma definição para a Síndrome do Desconforto Respiratório.

Este comitê recomendou que um novo termo, a Lesão Pulmonar Aguda fosse introduzida e definida como uma síndrome inflamatória com aumento da permeabilidade associado a uma ampla anormalidade clínica radiológica e fisiológica que não pode ser explicada, mas pode coexistir com hipertensão pulmonar. Está associada frequentemente com sepse, aspiração, pneumonia primária ou politrauma e menos comumente com politransfusão, embolia gordurosa, pancreatite entre outros (BERNARD et al., 1994; ANTONIAZZI et al., 1998; BALLARD-CROFT et al., 2012).

Também foi designado o termo Agudo e não mais Adulto para a Síndrome do Desconforto Respiratório (SDRA) para pacientes com LPA com piora da oxigenação (BERNARD et al., 1994). A diferença entre as duas situações é o grau de oxigenação; enquanto na LPA a relação da pressão parcial de $\mathrm{O}_{2}$ pela fração inspirada de $\mathrm{O}_{2}\left(\mathrm{PaO}_{2} / \mathrm{FiO}_{2}\right)$ é menor que 300, na SDRA esta relação é menos que 200 (GALHARDO e MARTINEZ, 2003; AMATO et al., 2007).

\subsubsection{Epidemiologia}

Apesar da padronização de definições para a LPA e SDRA pelo Consenso Americano-Europeu, muitos estudos apresentam os dados epidemiológicos sem distinção entre as síndromes.

Encontramos, ainda, diferenças regionais significativas na sua incidência devido a uma série de fatores, como etiologia, gestão, diferenças na estrutura com cuidados em saúde e na implementação em cuidados intensivos (BERSTEN et al., 2002).

A incidência de LPA / SDRA foi relatada como sendo 80 por 100.000 pessoas-anos, com uma taxa de mortalidade de 40\% nos Estados Unidos (FANG, BAI e WANG, 2012), gerando custos hospitalares de aproximadamente 3 milhões ao ano (RINCON et al., 2012). Quando associada à sepse, estudos indicam uma taxa de mortalidade de 30-50\% (CRIBBS, MATTHAY e MARTIN, 2010; DONG et al., 2013).

Um estudo prospectivo realizado em uma Unidade de Cuidados Intensivos Pediátricos, na China, indica que a incidência de SDRA em pacientes criticamente doentes foi de $2,7 \%$ com uma taxa de mortalidade de 44,8\% (FANG, BAI e WANG, 2012). Estudos 
relatam uma incidência de 35\% de SDRA associada a pacientes com lesão renal aguda (DOI et al., 2011), e uma taxa de mortalidade de 5-25\% para pacientes com LPA associada à transfusão sanguínea (BLATYTA et al., 2013).

No Brasil, pesquisadores realizaram um estudo prospectivo seguindo os critérios do Consenso Americano-Europeu para LPA/SDRA, no período de 1999 a 2000. Encontraram uma taxa de mortalidade para pacientes com LPA de $44 \%$ e $46,7 \%$ para SDRA (FIALKOW et al., 2002).

Segundo Ando et al., apesar da utilização de novas estratégias de ventilação mecânica associada ao tratamento dessas síndromes, o prognóstico continua desfavorável e as taxas de mortalidade altas (20-50\%). Ressaltam ainda um provável aumento da prevalência dessas síndromes devido ao envelhecimento populacional em associação a outras comorbidades, prevendo um aumento ainda maior nesses índices de mortalidade (ANDO et al., 2012).

\subsubsection{Fisiopatologia}

A LPA é o termo usado para descrever a resposta pulmonar a lesão que ocorre diretamente nos pulmões ou como consequência da lesão ou inflamação em outros locais do organismo.

O endotélio capilar é uma barreira seletivamente permeável que separa os componentes do sangue a partir do tecido circundante (TOYA e MALIK, 2012). No pulmão, como nos outros órgãos, o endotélio é um participante crítico em vários processos, tais como a permeabilidade vascular, coagulação e cascatas de anticoagulação, regulação do tônus vascular, interações com o sistema imune, formação de novos vasos por vasculogênese e angiogênese e na regulação da perfusão (VOELKEL e ROUNDS, 2009; EVORA, CELOTTO e CAPELLINI, 2011).

Os pulmões são vulneráveis a lesões inflamatórias porque os mediadores são liberados na circulação e os mesmos recebem a totalidade do débito cardíaco. Como consequência, os neutrófilos são atraídos, tornam-se ativos e liberam mediadores inflamatórios, como oxidantes e proteases, citocinas pró-inflamatórias e moléculas prócoagulantes, que lesam diretamente o epitélio alveolar e o endotélio vascular, propagando, dessa forma, o processo inflamatório (WIEDEMANN, MATTHAY e GILLIS, 1990; WARE e MATTHAY, 2000; MATTHAY e ZEMANS, 2011).

Há evidências, ainda, de que o NO exerce um papel importante na patogênese da LPA, contribuindo com o aumento da permeabilidade vascular e do edema através de 
mudanças no fluxo sanguíneo local (BRIGHAM e MEYRICK, 1986; KNOWLES e MONCADA, 1994; EVGENOV et al., 2002).

Desse modo, as barreiras habitualmente responsáveis por impedir o edema alveolar são perdidas. A quebra da barreira representada pela membrana alvéolo-capilar determina o influxo de líquido rico em proteínas para dentro dos espaços alveolares, gerando aumento da permeabilidade vascular levando ao quadro de edema pulmonar e insuficiência respiratória aguda grave. (PINHEIRO et al., 2007; VOELKEL e ROUNDS, 2009; MATTHAY e ZEMANS, 2011)

O influxo de líquido rico em proteínas para o interior dos alvéolos altera a integridade do surfactante pulmonar. A redução do surfactante favorece o colapso alveolar que, associado ao edema, determina importante prejuízo nas trocas gasosas e na mecânica pulmonar (WIEDEMANN, MATTHAY e GILLIS, 1990; WARE e MATTHAY, 2000; GALHARDO e MARTINEZ, 2003; PINHEIRO et al., 2007).

O dano causado no endotélio capilar ou no epitélio pulmonar pode ocorrer por fatores pulmonares ou extrapulmonares, causando lesões através de mecanismos diretos, como por exemplo, embolia gordurosa, aspiração de conteúdo gástrico, pneumonia, lesão inalatória, contusão pulmonar; ou indiretos, como por exemplo, sepse, traumatismo, pancreatite, politransfusão, choque (QUELUZ, DEFAVERI e EL--FAKHOURI, 1997; GALHARDO e MARTINEZ, 2003; AMATO et al., 2007; DA CUNHA et al., 2011; MATTHAY e ZEMANS, 2011; VILLAR, BLANCO e KACMAREK, 2011).

Atualmente, não se encontra relatos da existência de um tratamento específico para a LPA. Para a proposição do mesmo, é fundamental a identificação correta do agente causador, sobretudo porque somente com a eliminação da causa é possível interromper o ciclo da lesão (GALHARDO e MARTINEZ, 2003; RODRIGUES, 2003).

\subsubsection{Edema Pulmonar}

O edema pulmonar é definido pelo aumento de líquido no pulmão proveniente dos vasos sanguíneos. Este líquido acumula-se no interstício pulmonar antes de invadir os alvéolos (BASILE FILHO e CAPONE NETO, 1988; ATALAY et al., 2010; MATTHAY e ZEMANS, 2011).

Na LPA, a passagem de líquido para o alvéolo pode ser provocada ou agravada por alterações de permeabilidade da membrana alvéolo-capilar com pressão hidrostática e pressão capilar pulmonar normais ou baixas (pressão de oclusão da artéria pulmonar $\leq 18 \mathrm{mmHg}$ ), levando a um edema pulmonar não-hemodinâmico ou não-cardiogênico, rico em proteínas de 
alto peso molecular (BASILE FILHO e CAPONE NETO, 1988; RODRIGUES, 2003; ATALAY et al., 2010; MATTHAY e ZEMANS, 2011).

A instalação desse edema não-cardiogênico ocasionará a diminuição da complacência pulmonar (Cst,s=VC/ (Pplat-PEEPtotal)), aumento do shunt, alteração da relação ventilação/perfusão, com consequente hipoxemia refratária à administração de oxigênio (GALHARDO e MARTINEZ, 2003; RODRIGUES, 2003).

No processo de resolução da LPA, é necessária a reabsorção desse líquido do espaço alveolar. O mecanismo de clearance do edema alveolar ocorre devido ao desenvolvimento de gradientes osmóticos pela ação de canais de sódio e, possivelmente, cloro, localizados nas membranas de pneumócitos do tipo II. Estudos têm demonstrado que esse clearance está reduzido em pacientes com LPA, mesmo na fase inicial da lesão, levando a menor sobrevida desses pacientes (WARE e MATTHAY, 2001; MATTHAY, 2002; GALHARDO e MARTINEZ, 2003; MATTHAY e ZEMANS, 2011).

\section{4. Ácido Oleico}

O AO é um ácido graxo insaturado que provoca lesão pulmonar grave, ao contrário das gorduras neutras. Atua ligando-se ao cálcio constituinte das pontes intercelulares, removendo esse íon e formando sabões, enfraquecendo as junções celulares com consequente aumento da permeabilidade capilar. Possui também ação tóxica direta provocando necrose parenquimatosa e lesão endotelial. Sua presença na microcirculação desencadeia fenômenos tromboembólicos, mecânicos ou reflexos, que causam diminuição da perfusão e hipóxia (QUELUZ, DEFAVERI e EL--FAKHOURI, 1997; LIU et al., 2013).

Teoricamente, o modelo com AO induz LPA por mecanismo direto, causado pela EG. Sabe-se que os êmbolos gordurosos se propagam inicialmente através da circulação venosa, acometendo primariamente os pulmões. Em muitos casos podem atravessar a circulação pulmonar ou mesmo o septo inter-atrial através da circulação arterial (FILOMENO et al., 2005).

O mecanismo pelo qual o AO provoca a LPA ainda é incerto. Sugere-se que os danos causados pela ligação direta do AO nas membranas biológicas podem desempenhar um papel importante (MATUTE-BELLO, FREVERT e MARTIN, 2008; WANG, BODENSTEIN e MARKSTALLER, 2008; BALLARD-CROFT et al., 2012).

Porém, estudos recentes demonstram um aumento de neutrófilos pulmonares com acentuada aderência ao endotélio capilar pulmonar, após injeção intravenosa (i.v.) de AO. Os neutrófilos fixados ao endotélio liberam enzimas proteolíticas de seus lisossomos 
(especialmente a mieloperoxidase) as quais acabam por "digerir" as células endoteliais e alveolares. Desta forma, temos aqui a ação lesiva indireta dos ácidos graxos, compondo a “teoria atual” da gênese da lesão pulmonar na EG (FILOMENO et al., 2005).

Contudo, são muitas as similaridades entre a lesão pulmonar induzida por $\mathrm{AO}$ e àquelas observadas em pacientes acometidos com LPA. Observam-se sinais evidentes de edema intersticial e intra-alveolar (MATUTE-BELLO, FREVERT e MARTIN, 2008; CROCKER e JONES, 2014), trombos, congestão vascular e membrana hialina (BOUMGARTEN, DALMARCO e GUIMARÃES, 2008), aumento da pressão de vias aéreas, redução da complacência pulmonar e aumento da permeabilidade do endotélio (GOEBEL et al., 2014).

Como resultado final de toda essa complexa cadeia de alterações, temos 0 estabelecimento de extensas áreas de pulmão nas quais os alvéolos são perfundidos, mas não ventilados ("efeito shunt") e outras nas quais ocorre o inverso, isto é, existem alvéolos que são ventilados, mas não perfundidos ("efeito espaço-morto"). A consequência direta do "efeito shunt" é a queda progressiva da $\mathrm{PO}_{2}$ arterial, enquanto que o "efeito espaço-morto" tende a aumentar progressivamente a $\mathrm{PaCO}_{2}$ (FILOMENO et al., 2005).

Queluz et al. (1997) realizaram um estudo morfológico das alterações pulmonares agudas e crônicas induzidas em ratos pela injeção intravenosa de AO e observaram que o ácido provoca agudamente edema alveolar difuso e focos hemorrágicos intra-alveolares, comprovando a eficácia do modelo.

\section{5. Óxido Nítrico (NO)}

O NO é um radical gasoso diatômico, com meia vida muito curta, que é sintetizado endogenamente a partir do aminoácido L-arginina pela ação das enzimas Óxido Nítrico Sintase (NOS) (BARNES e BELVISI, 1993; EVGENOV, SVEINBJORNSSON e BJERTNAES, 2001; BALDO, 2009). Ele ativa a GCs, a qual, diminuindo o cálcio intracelular, facilita o relaxamento da musculatura lisa vascular (EVORA, CELOTTO e CAPELLINI, 2011).

Três tipos de isoformas da NOS foram identificados: a endotelial (eNOS), a neuronal (nNOS) e a induzida (iNOS) (EVGENOV et al., 2002; HATAISHI et al., 2006).

As duas primeiras são constitutivas e expressas nas células endoteliais e neurônios, respectivamente. São dependentes de cálcio/calmodulina e liberam pequenas quantidades de NO (EVORA, CELOTTO e CAPELLINI, 2011).

A iNOS é independente de cálcio e é estimulada a partir da ativação de macrófagos 
e por fatores pró-inflamatórios, como endotoxinas bacterianas, interleucina-1 (IL-1), fator de necrose tumoral $\alpha$ (TNF- $\alpha$ ) e interferon $\gamma$ (IFN- $\gamma$ ), gerando produção sustentada e liberação de grandes quantidades de NO (EVGENOV, SAGER e BJERTNAES, 2001; FERNANDES, 2006; SAMANO, 2008).

O NO promove a vasodilatação, formação de edema e modula as terminações nervosas sensoriais terminais que é a marca característica da resposta inflamatória (BALDO, 2009).

A vasodilatação e a citotoxicidade mediadas pelo NO podem ser reduzidas por diferentes abordagens farmacológicas, incluindo a inibição da GCs. Espera-se que a restauração do tono vascular melhore as alterações patológicas, com efeitos benéficos para a função orgânica (EVORA, CELOTTO e CAPELLINI, 2011).

\subsection{Azul de Metileno (AM)}

O AM foi descoberto por Heinrich Caro em 1876 e, inicialmente foi usado como corante citológico e como indicador de oxiredução (BALDO, 2009; DIAZ, 2009). Em 1891, Guttmann e Ehrlich foram os primeiros a relatar as propriedades anti-maláricas do AM. A coloração com AM também deu início a pesquisa de drogas modernas (SCHIRMER et al., 2011).

Em 1910, Paul Ehrlich utilizou o AM para distinguir células vivas, que se tornavam azuis, de células mortas que se mantinham incolores, o que lhe rendeu o título de "Pai da Quimioterapia”, ressaltando-se que ele notabilizou-se, entre outras coisas, por utilizar o AM no tratamento de malária (EVORA, CELOTTO e CAPELLINI, 2011).

É um corante derivado das tiazidas (C16H18CIN3S, 3H2O) quimicamente conhecido como cloreto de 3,7 Bis-di-metilamino fenazationium tri-hidratado. Apresenta-se como um pó de aspecto cristalino de coloração azul-escuro esverdeado, inodoro, solúvel em água, álcool e clorofórmio (LO, DARRACQ e CLARK, 2014).

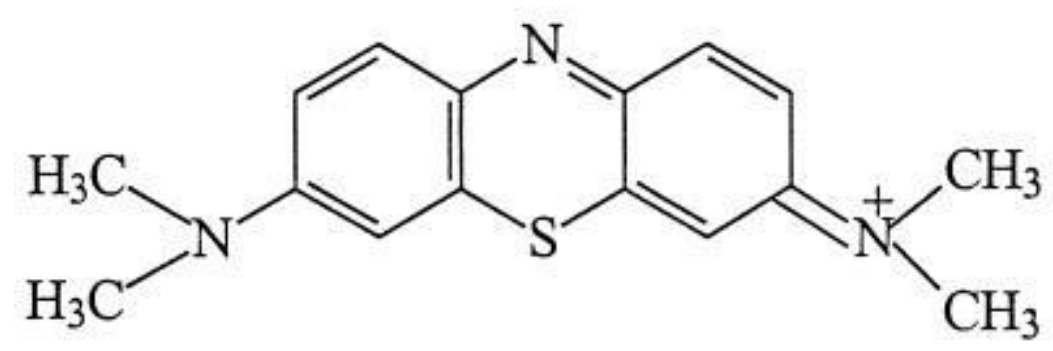

Figura 1 Estrutura molecular do Azul de Metileno. Reproduzido a partir de He \& Tebo, 1998. 
Para administração intravenosa, o AM é dissolvido em água estéril para atingir a concentração de 1\% (10 mg/mL). Na Grã-Bretanha, o National Poisons Information Service recomenda que a dose intravenosa máxima de $\mathrm{AM}$ seja de $4 \mathrm{mg} / \mathrm{kg}$. No entanto, há relatos de seu uso em até $7 \mathrm{mg} / \mathrm{kg}$, sem efeitos colaterais (EVORA, CELOTTO e CAPELLINI, 2011).

Os efeitos do AM dão-se principalmente pela interação com a via NO-GMPc, inibindo a ação da enzima GCs, bloqueando, assim, o aumento da GMPc, a via efetora final da produção de NO com ação vasodilatadora (DIAZ, 2009; BALDO et al., 2013).

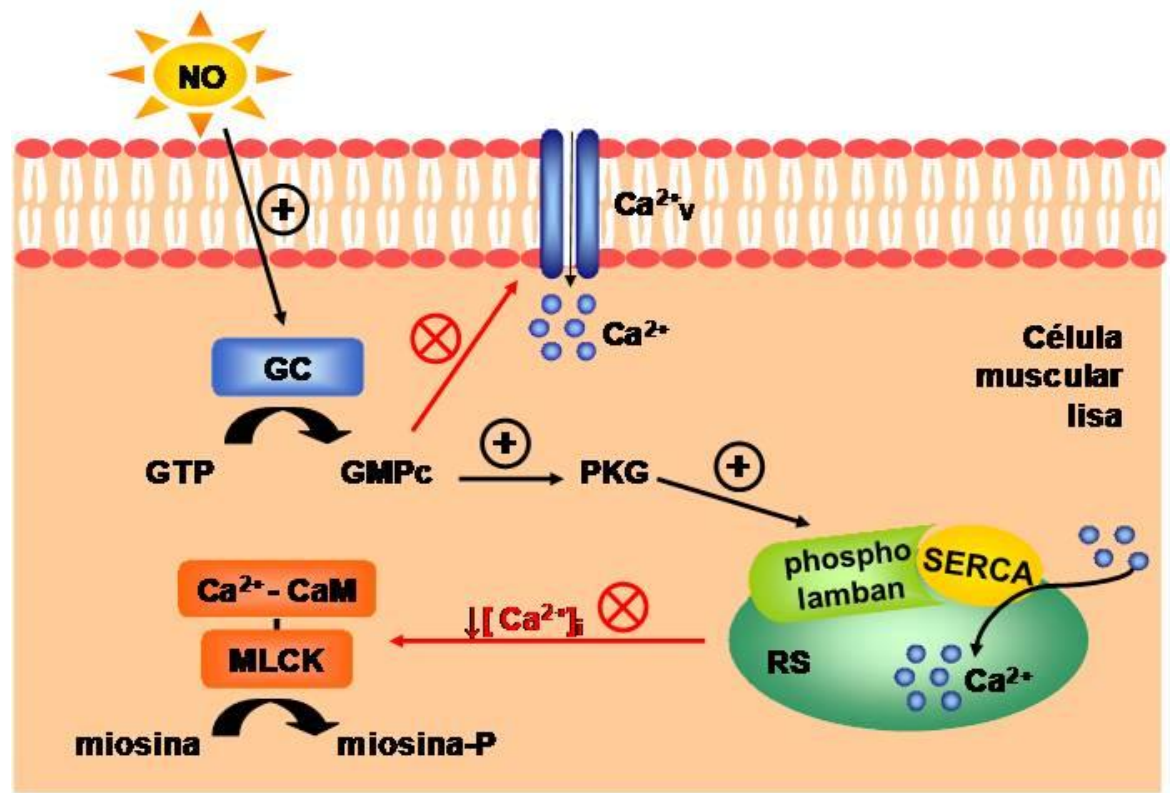

Figura 2 Mecanismo de relaxamento da célula muscular lisa vascular mediado pelo óxido nítrico. Reproduzido a partir de Baldo, 2009. O óxido nítrico (NO) ativa a guanilato ciclase (sGC) convertendo guanosina trifosfato (GTP) em guanosina monofosfato cíclica (cGMP). O cGMP bloqueia canais para cálcio dependentes de voltagem $(\mathrm{Ca} 2+\mathrm{v})$ presentes na membrana celular e ativa a proteína quinase dependente de cGMP (PKG). A PKG fosforila a phospholamban, que por sua vez, ativa a ATPase (SERCA), a qual sequestra Ca2+ para dentro do retículo sarcoplasmático (RS). Com a redução na concentração intracelular de $\mathrm{Ca} 2+$, a quinase da cadeia leve da miosina (MLCK) não pode ser ativada pelo complexo cálcio-calmodulina (Ca2+-CaM), e se a cadeia leve da miosina não é fosforilada (miosina-P), não ocorre contração

Estudos experimentais avaliando os efeitos do AM após indução de LPA por endotoxina lipopolissacarideo (LPS) demonstram um efeito protetor dessa droga, atenuando o edema e a hipertensão pulmonar (EVGENOV, SAGER e BJERTNAES, 2001; EVGENOV et $a l .$, 2002; KIROV, EVGENOV e BJERTNAES, 2003), e apresentando melhora da função ventricular direita (EVGENOV, SVEINBJORNSSON e BJERTNAES, 2001; EVGENOV et al., 2002).

Além da ação sobre a GCs, o AM também inibe a produção de radicais superóxido por agir como um receptor alternativo de elétrons da xantina oxidase (GRECA et al., 2004).

Há relatos que o AM ainda pode inibir a síntese de NO agindo diretamente sobre o grupo heme da eNOS e iNOS. Acredita-se que os alvos de inibição pelo AM sejam enzimas 
que possuem o grupo heme. Sugere-se que o AM seja um inibidor específico e potente da NOS. (MAYER, BRUNNER e SCHMIDT, 1993b; a). Porém, alguns autores relataram que a utilização do AM é atraente pelo fato de não interferir na síntese fisiológica do NO pela NOS. Sua ação ocorreria ao nível do alvo do NO, ou seja, na musculatura lisa vascular, impedindo a ativação da GCs e, com isso, diminuindo os níveis de GMPc (ANDRADE et al., 1996).

$\mathrm{Na}$ clínica, o AM vem sendo amplamente utilizado no controle de estados vasoplégicos associados à sepse, à anafilaxia e vasoplegias de causas desconhecidas observadas em pacientes submetidos a cirurgias de cunho cardíaco ou não (LO, DARRACQ e CLARK, 2014). A inibição precoce da NOS pelo AM, mesmo que de modo parcial, implica em níveis menores de nitrito e nitrato o que leva a melhora do débito cardíaco e da pressão arterial média. A administração pré-operatória do AM proporciona resistência vascular sistêmica adequada, reduzindo a incidência e a gravidade da síndrome vasoplégica em pacientes de alto risco (BALDO, 2009).

Há ainda relato de caso na literatura de paciente com crise carcinóide e SDRA refratária as terapias convencionais. Após a administração do AM foram observadas melhorias substanciais hemodinâmicas e de oxigenação. Este caso destaca o potencial do AM como uma opção terapêutica adjuvante em crises carcinóides (VAN DIEPEN et al., 2013).

Na Divisão de Cirurgia Torácica do Departamento de Cirurgia e Anatomia da FMRP-USP, outro caso foi relatado onde um jovem viciado em drogas com endocardite nativa da válvula aórtica foi submetido à cirurgia de troca valvar por prótese de duplo folheto. Evolui com hipotensão resistente a aminas, débito cardíaco elevado, baixa resistência vascular sistêmica, edema pulmonar e baixa saturação arterial de oxigênio. Após administração de AM, o débito cardíaco diminuiu gradualmente com aumento da resistência vascular sistêmica. Além disso, ocorreu surpreendente e rápida resolução do edema pulmonar resultando em saturação de oxigênio arterial mais adequada (EVORA e RODRIGUES, 2006).

O AM é usado há muitos anos em clínica, por exemplo, no tratamento da metahemoglobinemia e como antisséptico urinário. Não apresenta, até o momento, nenhuma contraindicação que clinicamente impeça o seu uso seguro. A sua utilização não significa a introdução de uma nova droga, o que implicaria em diversos rigores científicos e éticos (EVORA, CELOTTO e CAPELLINI, 2011). 


\section{OBJETIVOS}

\subsection{Geral}

Verificar o efeito do AM como profilaxia e como tratamento do edema pulmonar presente na LPA, ministrando-o antes e após a indução da lesão pulmonar por AO.

\subsection{Específico}

Analisar, por meio de indicadores de LPA induzida por AO, a inibição da ativação da enzima GCs pelo AM, bloqueando a via NO-GMPc. 


\section{MATERIAL E MÉTODOS}

\subsection{Animais}

Foram utilizados ratos machos da linhagem Wistar, pesando entre 200-300g, provenientes do Biotério Central do Campus de Ribeirão Preto da Universidade de São Paulo (USP). Os animais foram acondicionados em ambiente com temperatura $\left(22-25^{\circ} \mathrm{C}\right)$ e ciclo claro/escuro (12:12 horas) controlados e livre acesso à água e à ração.

Os procedimentos com os animais, bem como os protocolos experimentais deste estudo foram aprovados pela Comissão de Ética em Experimentação Animal (CETEA) da Faculdade de Medicina de Ribeirão Preto (FMRP) com o número de protocolo 086/2013.

\subsection{Desenho experimental}

Os animais foram divididos aleatoriamente em 5 grupos:

$\checkmark$ Sham: os animais foram anestesiados e receberam infusão i.v. de salina em bolus.

$\checkmark$ Azul de Metileno (AM): os animais receberam infusão de AM por $2 \mathrm{~h}$.

$\checkmark$ Ácido Oleico (AO): os animais receberam infusão de $\mathrm{AO}$ em bolus.

$\checkmark$ Azul de Metileno/Ácido Oleico (AM/AO): os animais receberam a infusão de AM por 2h. Após 5 min do início da infusão do AM, foi administrado AO em bolus.

$\checkmark$ Ácido Oleico/Azul de Metileno (AO/AM): os animais receberam a infusão de AO em bolus e, após $2 \mathrm{~h}$, foi infundido AM por mais $2 \mathrm{~h}$.

Foi realizada a coleta de material para análise de todos os grupos 4h após o início dos experimentos. 


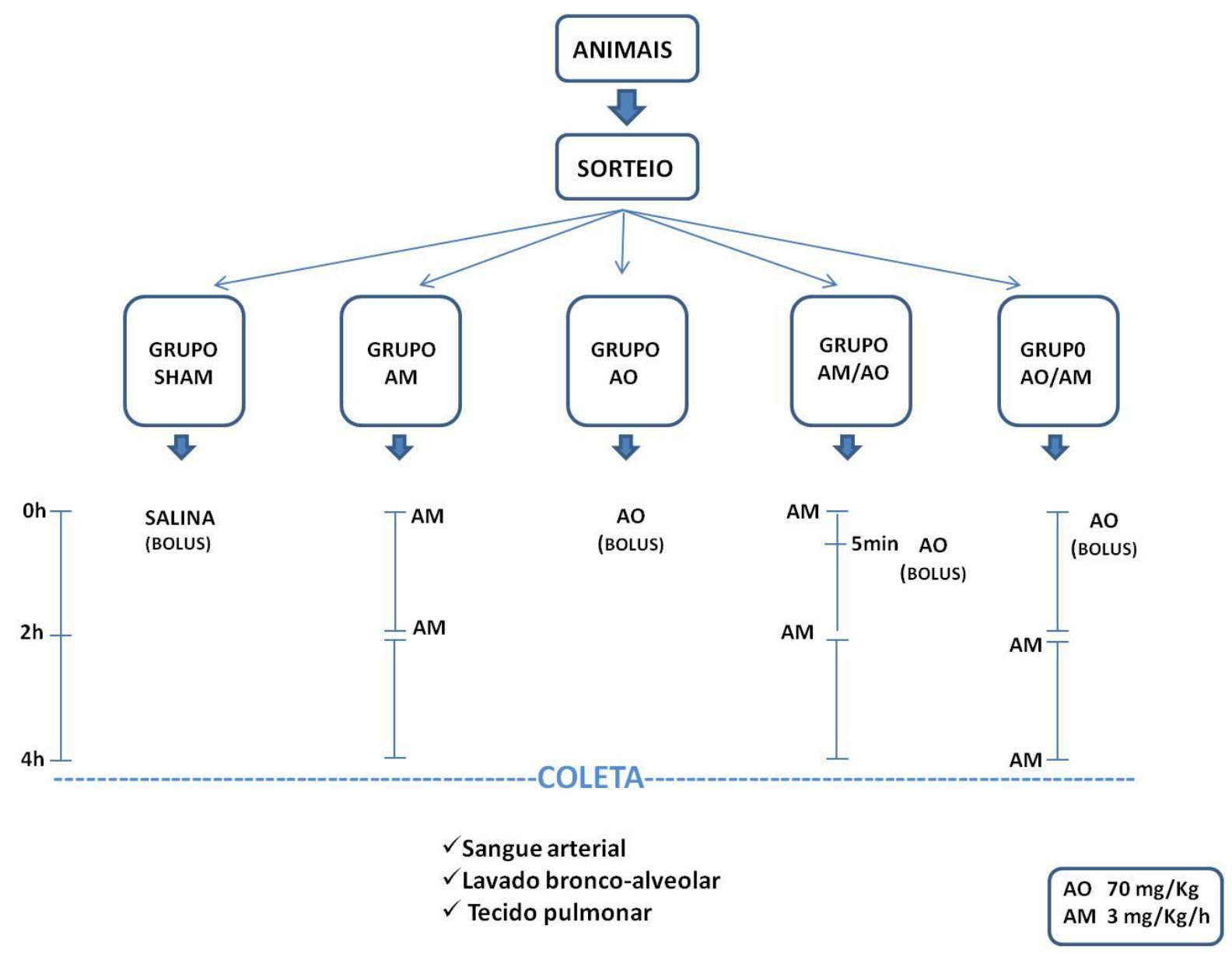

Figura 3 Esquema experimental

\subsection{Indução da lesão pulmonar aguda}

Para a indução da LPA, os animais receberam a infusão i.v de $70 \mathrm{mg} / \mathrm{kg}$ de AO (Sigma Chemical Company, EUA) em bolus pela veia femural esquerda. Os animais do grupo controle receberam salina ao invés de AO.

\subsection{Tratamento com azul de metileno}

Os animais dos grupos tratados após a indução da lesão pulmonar receberam infusão i.v. de $3 \mathrm{mg} / \mathrm{kg}$ em bolus seguido da infusão de $3 \mathrm{mg} / \mathrm{kg} / \mathrm{h}$ de AM (Sigma Chemical Company, EUA) pela veia femoral esquerda, utilizando uma bomba de infusão (Syringe Infusion Pump, Harvard Apparatus, South Natick, MA, EUA). O tempo de infusão foi de $2 \mathrm{~h}$.

\subsection{Técnica anestésica e operatória}

Todos os animais foram submetidos à medicação pré-anestésica com injeção 
intraperitonial (i.p) de Uretano $(2 \mathrm{mg} / \mathrm{kg})$.

Os acessos, arterial e venoso, foram obtidos por dissecção e canulação da artéria e da veia femoral esquerda.

Após a coleta do sangue arterial os animais foram sacrificados por exsanguinação.

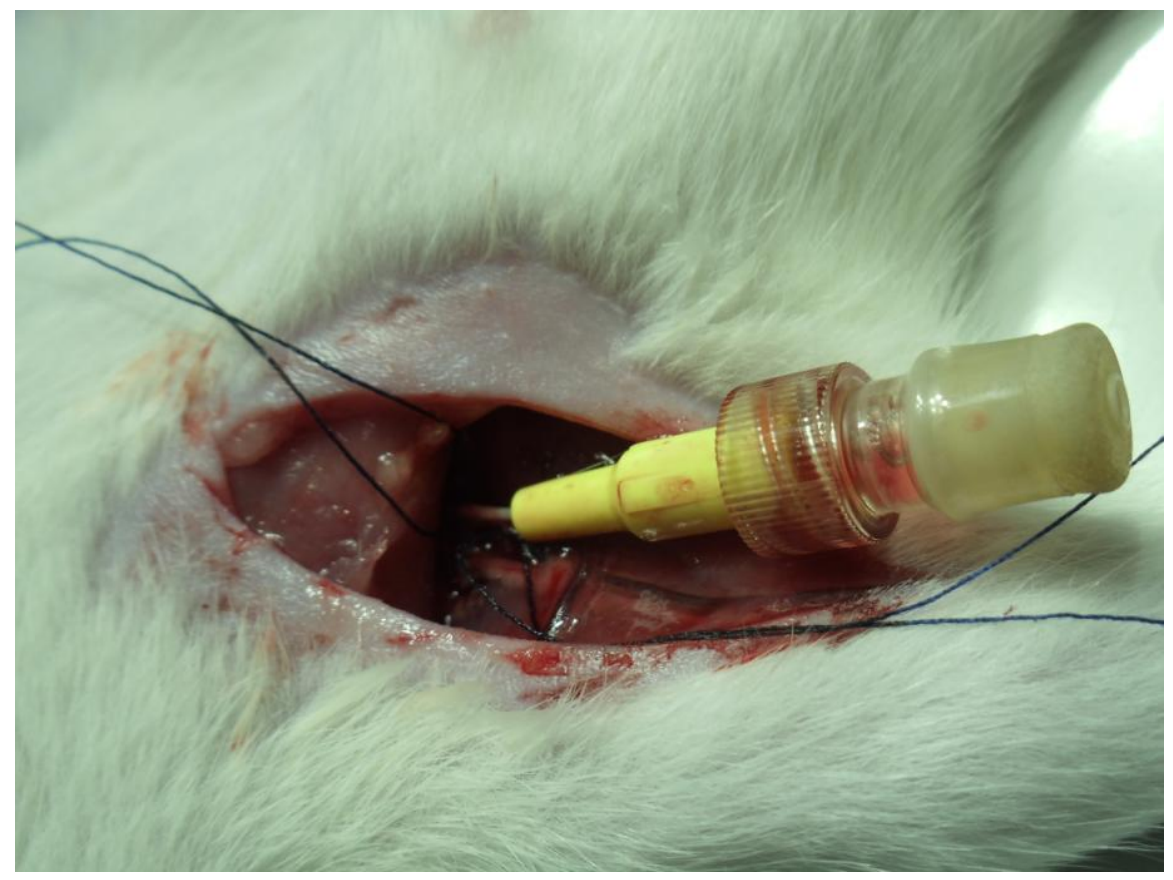

Figura 4. Imagem do processo de canulação da artéria femoral para coleta de sangue e infusão de drogas.

\subsection{Gasometria arterial}

As amostras de sangue arterial foram coletadas com o auxílio de uma seringa hipodérmica de $1 \mathrm{~mL}$ e imediatamente analisadas.

As dosagens foram realizadas por um aparelho de hemogasometria Gem Premier 3000 (Instrumentation Laboratory Co., Bedford, Massachusstes, EUA) previamente calibrado, utilizando-se cartucho próprio do tipo iQM 150 (GEM Premier iQM, Instrumentation Laboratory Co., Bedford, Massachusstes, EUA). Os resultados obtidos foram impressos pelo próprio aparelho.

As medidas bioquímicas de $\mathrm{PaO}_{2}$ foram obtidas, seguida do cálculo da relação $\mathrm{PaO}_{2} / \mathrm{FiO}_{2}$, com $\mathrm{FiO}_{2}$ de $21 \%$.

\subsection{Coleta do lavado bronco-alveolar (LBA)}

Após a morte dos animais, a caixa torácica foi aberta e a traqueia e os pulmões foram dissecados e retirados em bloco.

Para realizar a coleta do LBV, a traqueia foi cortada aproximadamente $2 \mathrm{~cm}$ acima da 
carina. Foi introduzida uma sonda de aspiração traqueal seletivamente no pulmão esquerdo, instilado $1 \mathrm{ml}$ de cloreto de sódio $(\mathrm{NaCl}$ 0,9\%) e realizado a aspiração com uma seringa hipodérmica de $2 \mathrm{~mL}$. Metade do volume instilado foi coletado para análise (Figura 5).

A amostra obtida foi armazenada em tubo de polipropileno e congelada em freezer próprio a $-70^{\circ} \mathrm{C}$ para posterior dosagem de proteínas totais.
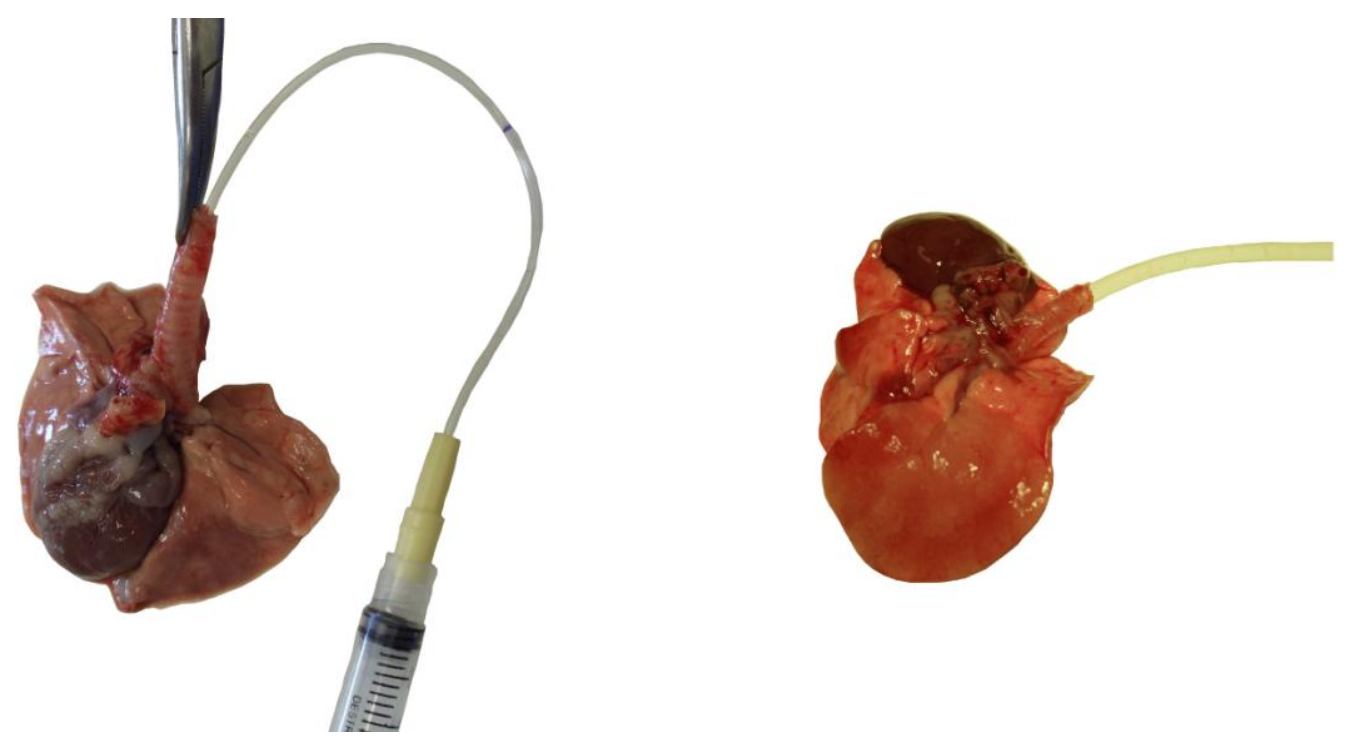

Figura 5. Método de coleta do lavado bronco-alveolar.

\subsection{Determinação indireta de $\mathrm{NO}$ pela dosagem de nitrito $\left(\mathrm{NO}^{2-}\right)$ e nitrato $\left(\mathrm{NO}^{3-}\right)$ plasmáticos e tecidual (NOx)}

As amostras de sangue foram coletadas, colocadas em tubo heparinizado (1:20) e centrifugadas (2500rpm; $\left.4^{\circ} \mathrm{C}, 15 \mathrm{~min}\right)$ para a separação do plasma.

O lobo superior do pulmão direito foi dissecado.

As amostras de plasma e pulmão foram armazenadas em tubo de polipropileno, colocadas imediatamente em nitrogênio líquido e armazenado em freezer $\left(-70^{\circ} \mathrm{C}\right)$ para posterior dosagem de nitrito/nitrato (NOx).

As dosagens indiretas de NO plasmático e no tecido pulmonar foram realizadas pela determinação dos níveis séricos de nitrito e nitrato utilizando-se o Sievers NO Analizer 280i (Sievers, Boulder, CO, EUA).

\subsection{Análise da relação peso úmido/peso seco (PU/PS) do pulmão}

O lobo inferior do pulmão direito foi dissecado e pesado em balança analítica de 
precisão de $0,001 \mathrm{~g}$ para obtenção do peso úmido.

Em seguida, foi colocado em estufa de secagem e esterilização há $60^{\circ}$ por 24 horas e pesado novamente para obtenção do peso seco.

Os valores obtidos foram utilizados para o cálculo da relação PU/PS.

\subsection{Análise histológica}

O lobo médio do pulmão direito foi coletado e cortado longitudinalmente. Uma fatia central de $2 \mathrm{~mm}$ foi armazenada em formol tamponado $10 \%$.

Após 24 horas de fixação em formol tamponado $10 \%$ (v/v), as amostras de pulmão passaram por desidratação progressiva (bateria de álcoois de baixa graduação até álcool absoluto: 50, 70, 80, 90, 95 e 100\% - v/v), seguida por diafanização em xilol e inclusão em parafina. Após microtomia (Micrótomo 2040, Reichert-Jung, Alemanha), cortes de $3 \mu \mathrm{m}$ de espessura foram colocados em lâminas e corados com hematoxilina/eosina (HE) para análise histológica em microscopia de luz.
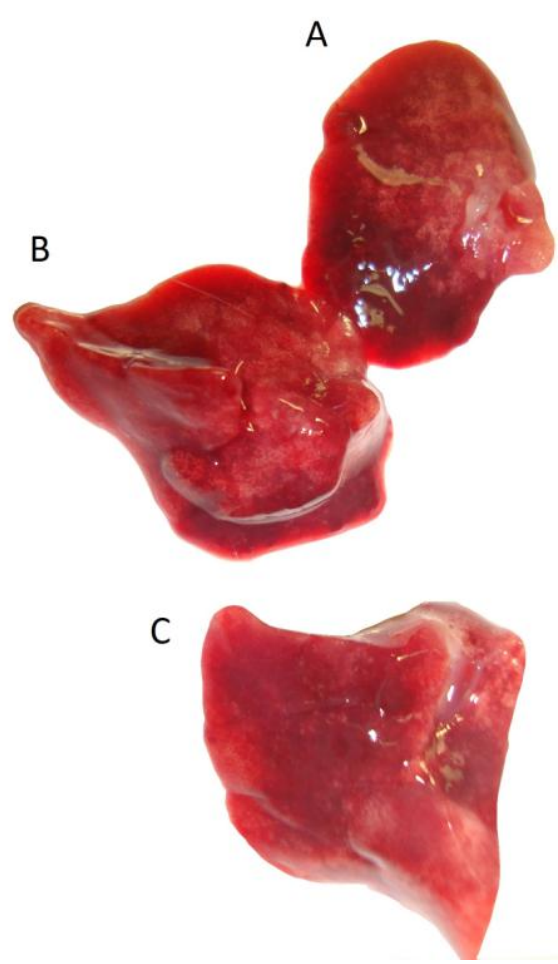

Figura 6. Lobo pulmonar direito (A- superior, B- médio e C-inferior).

\subsection{Análise estatística}

Os dados foram apresentados como média \pm EPM e comparados pela a análise de 
variância simples (one-way ANOVA), seguida do pós-teste de Tukey, utilizando o programa GraphPad Prism versão 5.0 (GraphPad Software Corporation, La Jolla, California, EUA).

O nível de significância adotado foi de $\mathrm{p}<0.05$. 


\section{RESULTADOS}

\subsection{Análise de gases}

Os dados mostraram uma relação $\mathrm{PaO} 2 / \mathrm{FiO} 2 \geq 300$ para todos os grupos, não sendo encontrado hipoxemia grave após 4 h de LPA com AO.

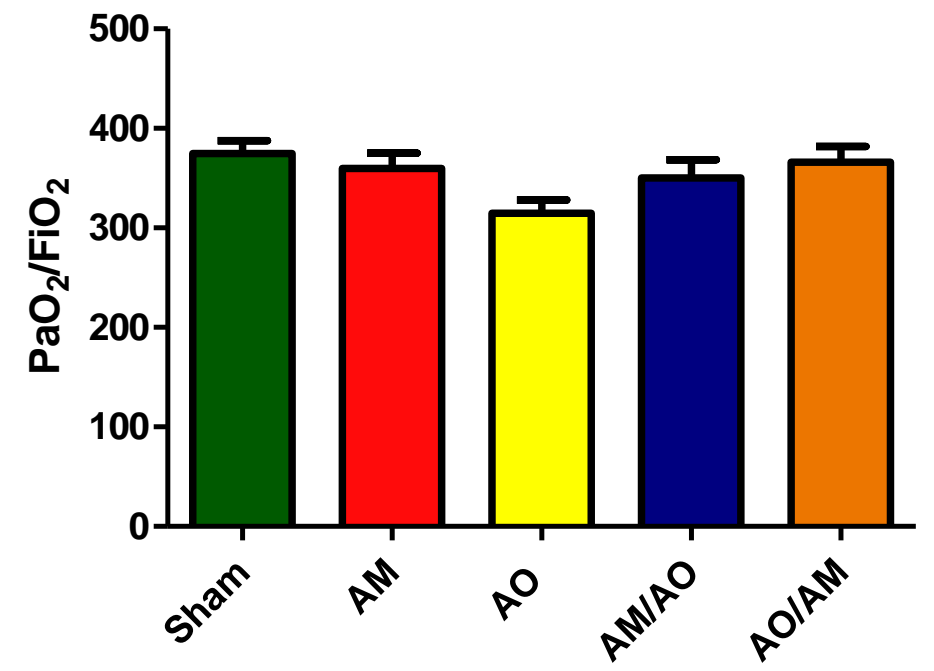

Figura 7. Relação $\mathrm{PaO} 2 / \mathrm{FiO} 2$ com FiO2 de 21\%. Grupo Sham n=10; Grupo AM n=11; Grupo AO n=11; Grupo $\mathrm{AM} / \mathrm{AO} \mathrm{n}=11$; Grupo AO/AM n=8. Os dados foram apresentados como média $\pm \mathrm{EPM}$.

\subsection{Alteração da permeabilidade pulmonar}

Foi observado um aumento no número de proteínas no lavado bronco-alveolar e na relação PU/PS no Grupo AO em relação aos grupos controle: Sham e AM. Esses dados confirmam a presença de lesão e alteração de permeabilidade pulmonar. (Figura 8 e 9).

Em relação aos grupos tratados com AM, ambos apresentaram melhora na permeabilidade pulmonar, com valores inferiores no número de proteínas no lavado e na relação PU/PS comparados ao Grupo AO. Porém, apenas o grupo pré-tratamento (AM/AO) apresentou diferença estatística na redução do extravasamento de proteínas no lavado (Figura 8). 


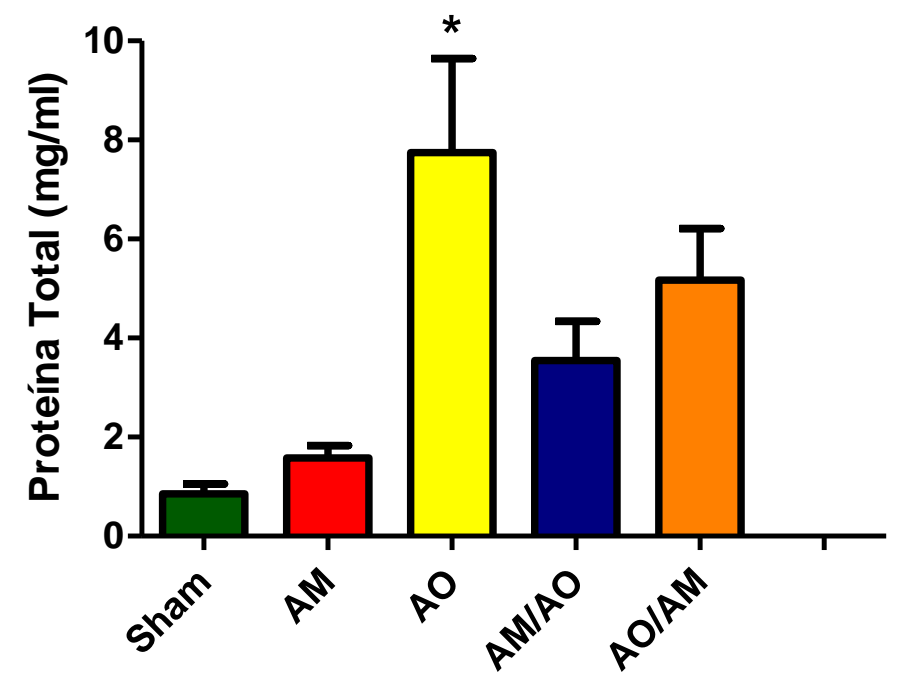

Figura 8. Dosagem de proteínas totais no lavado bronco-alveolar. Grupo Sham n=10; Grupo AM n=11; Grupo AO n=11; Grupo AM/AO n=11; Grupo AO/AM n=9. Os dados foram apresentados como média \pm EPM. * índica diferença significativa com p<0.05 em relação aos Grupos: Sham, AM e AM/AO.

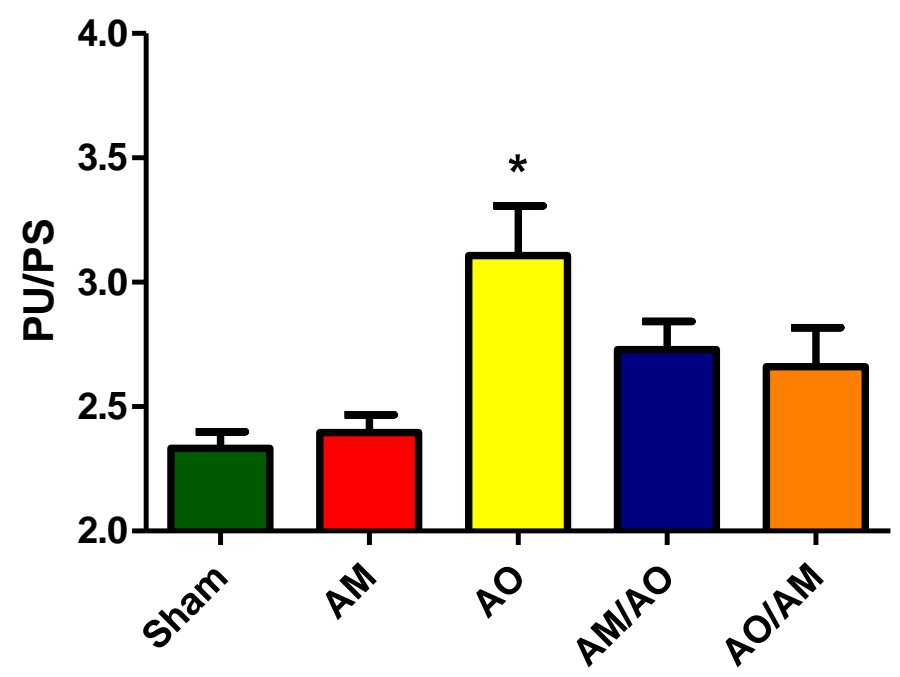

Figura 9. Relação PU/PS dos pulmões. Grupo Sham n=10; Grupo AM n=11; Grupo AO n=11; Grupo AM/AO $\mathrm{n}=11$; Grupo AO/AM n=09. Os dados foram apresentados como média \pm EPM. * índica diferença significativa com p<0.05 em relação aos Grupos: Sham, AM.

\subsection{Nitrito/Nitrato (NOx) plasmático e tecidual}

Os níveis de NOx tecidual encontrados no grupo de indução da LPA (AO) foram maiores do que nos demais grupos (Figura 10).

Com relação às análises plasmáticas, os grupos com LPA, tratados ou não (AO, $\mathrm{AM} / \mathrm{AO}, \mathrm{AO} / \mathrm{AM})$, apresentaram valores inferiores nos níveis de NOx quando comparados 
aos grupos controles (Sham e AM).

Não foi encontrada nenhuma diferença significativa entre os grupos.
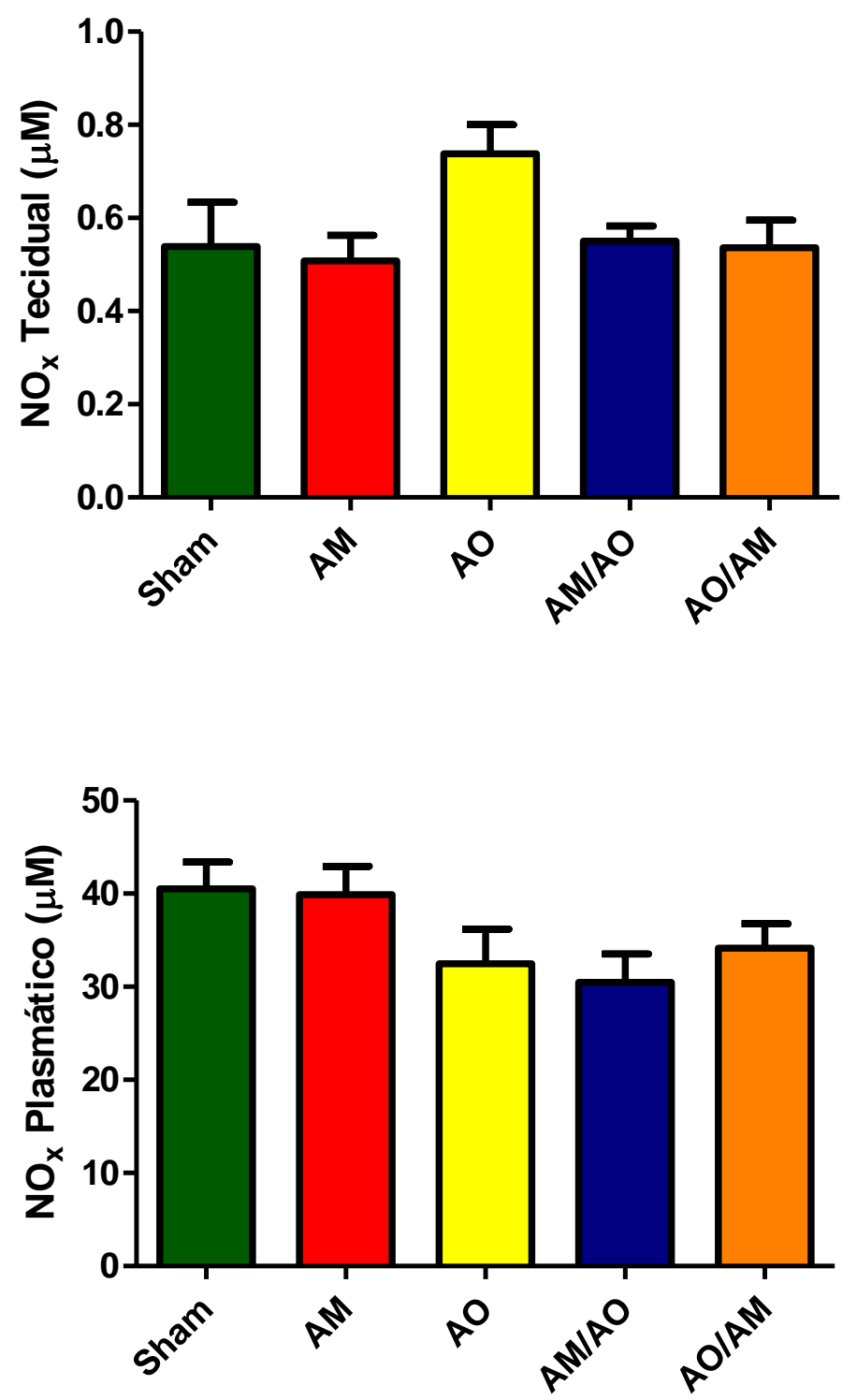

Figura 10. Análise do NOx plasmático e tecidual. Grupo Sham n=10; Grupo AM n=11; Grupo AO n=11; Grupo AM/AO n=11; Grupo AO/AM n=09. Os dados foram apresentados como média \pm EPM.

\subsection{Análise macroscópica e microscópica do tecido pulmonar}

Os pulmões foram analisados macro e microscopicamente.

$\mathrm{Na}$ macroscopia, o grupo AO mostrou congestão importante e difusa (Fig.11). Na microscopia, a congestão capilar foi intensa, acompanhada de múltiplos focos de edema 
alveolar, exsudato intra-alveolar proteico, áreas de hemorragia e infiltrado inflamatório neutrofílico, tanto no interstício quanto nos septos alveolares.

Chamou a atenção a presença de focos de necrose coagulativa nos septos alveolares relacionada às áreas de lesão previamente descritas. Em alguns pontos, o processo foi ainda mais proeminente, mostrando colapso alveolar e depósitos de membrana hialina. (Fig.12).

No grupo $\mathrm{AM} / \mathrm{AO}$, as alterações foram semelhantes, mas de menor monta. A principal diferença foi a diminuição das áreas de edema, exsudação e hemorragia. Entretanto, a necrose septal continuou presente e até mais facilmente visualizada.

No grupo AO/AM, houve também diminuição importante dos focos de lesão, mas essas foram mais proeminentes no grupo pré-tratamento.

Os grupos Sham e AM não apresentaram alterações significativas. (Fig.13).

A
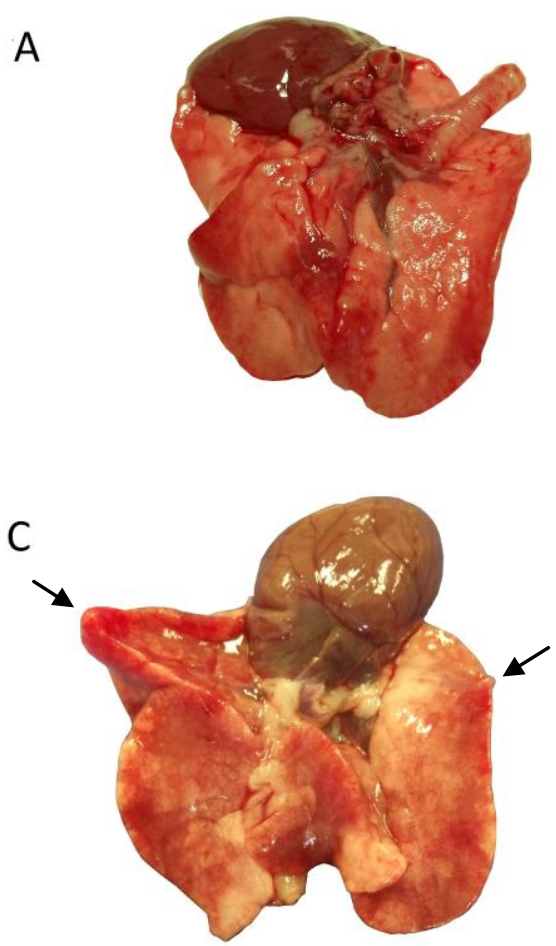

B
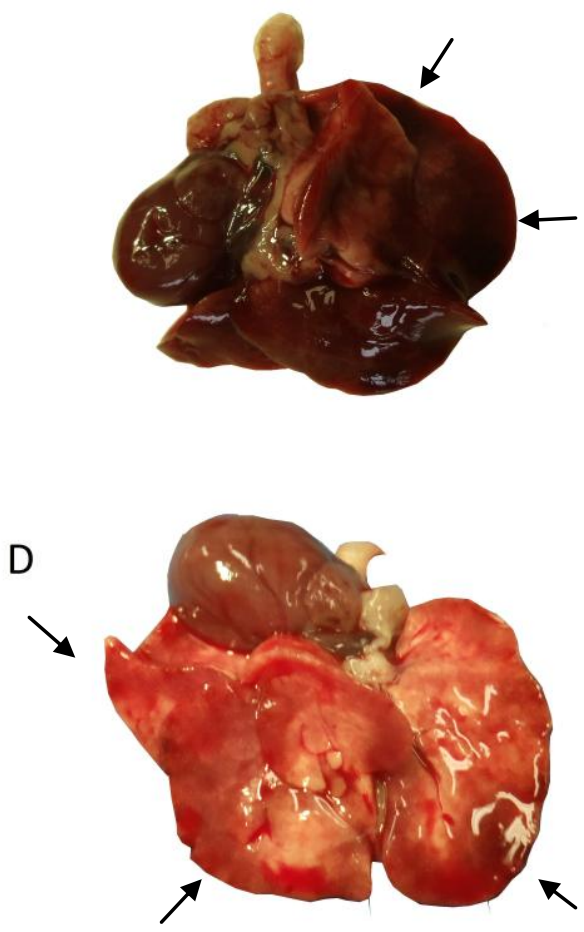

Figura 11. Imagem macroscópica do tecido pulmonar. A: Sham; B: Ácido Oleico (AO); C: Azul de Metileno/Ácido Oleico (AM/AO); D: Ácido oleico/Azul de Metileno (AO/AM). B: Pulmões armados, congestos, pesados, característico de edema intra-alveolar e com áreas subpleurais mais escuras, sugerindo hemorragia; $C$ : diminuição significativa do edema e da congestão, porém, permanecem focos de edema e hemorragia. D: redução do edema e da congestão, com focos de edema e hemorragia mais proeminentes. 


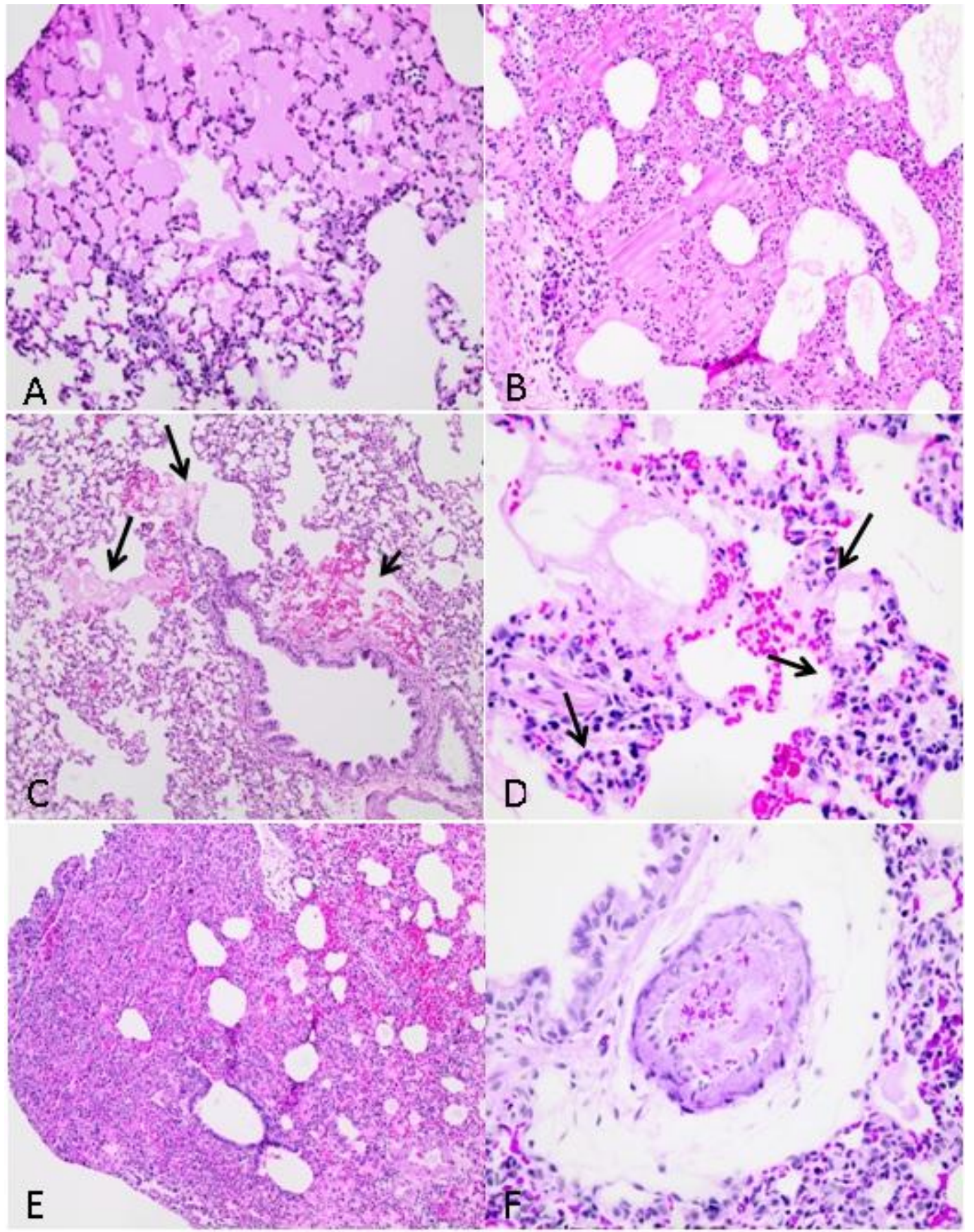

Fig. 12. Alterações microscópicas observadas nos pulmões após infusão de Ácido Oleico.

A. Edema intra-alveolar; HE, aumento original 20x. B. Exsudato intra-alveolar proteináceo; HE, aumento original 20x. C. Focos de necrose parenquimatosa (setas longas) associada a hemorragia (seta curta); HE, aumento original 10x. D. Detalhe da necrose parenquimatosa (septal) à esquerda associada à hemorragia e infiltração neutrofílica importante nos septos alveolares (setas); HE, aumento original 40x. E. Área de colapso dos alvéolos pulmonares; HE, aumento original 5x. F. Trombo fibrinoso em microcirculação; HE, aumento original 40x. 


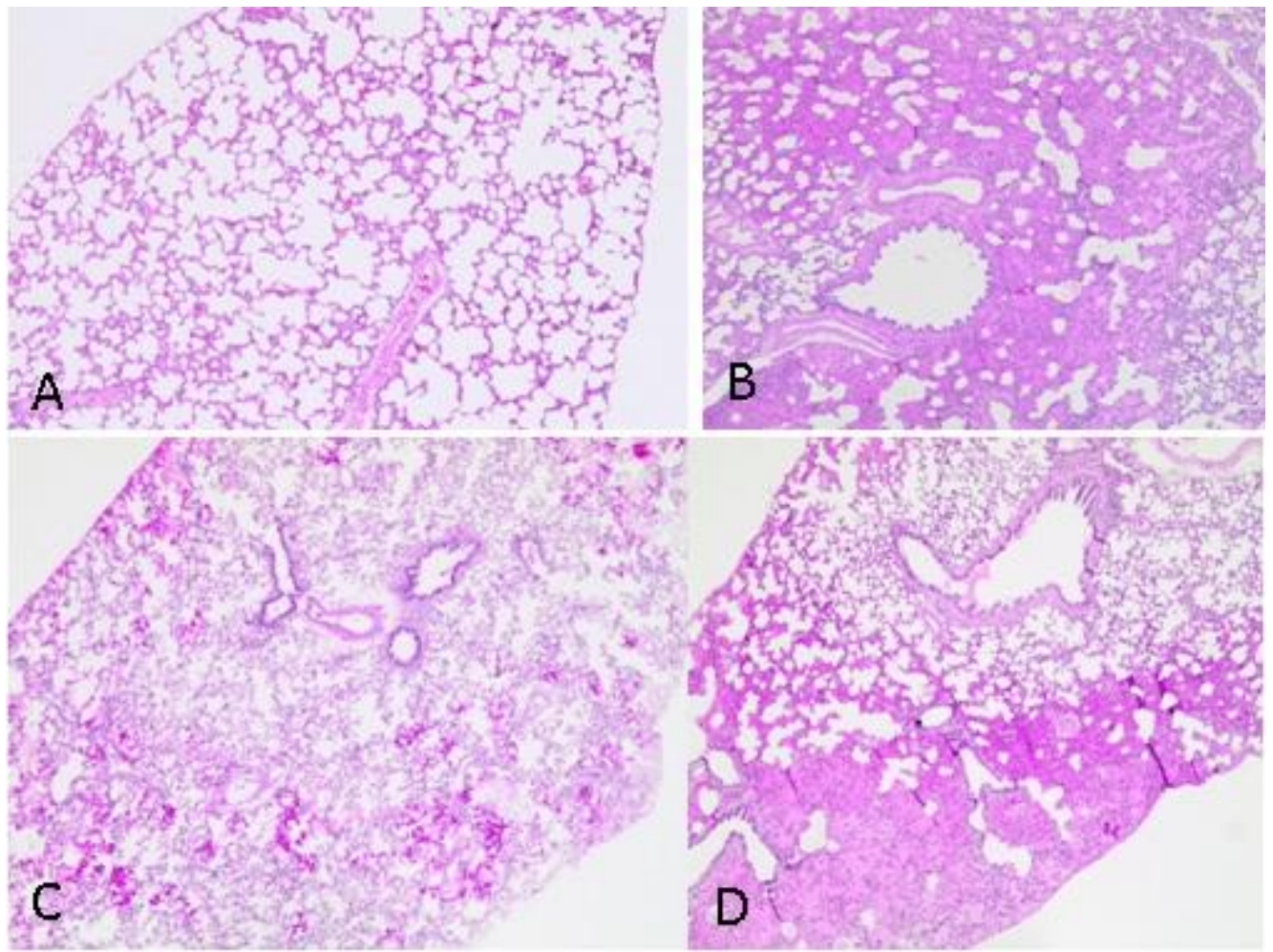

Fig. 13. Imagem panorâmica dos pulmões comparando os grupos analisados.

A. Grupo Sham - Pulmões sem alterações significativas. B. Grupo AO - Extensa área comprometida, com congestão importante, edema intra-alveolar e colapso alveolar. C. Grupo AM/AO - Permanência da congestão e focos de necrose parenquimatosa. Redução significativa do edema, seja fluido ou proteináceo. D. Grupo AO/AM - Diminuição das áreas de lesão com permanência de focos de edema e exsudação intra-alveolares; HE, aumento original 4x. 


\section{DISCUSSÃO}

Na LPA, como já mencionado, a integridade da barreira endotelial vascular é comprometida, levando a um aumento da permeabilidade vascular com influxo de líquido rico em proteínas para dentro dos espaços alveolares. O presente estudo foi realizado para avaliar os efeitos do AM no tecido pulmonar, com ênfase na permeabilidade capilar, inibindo-se a GCs em ratos com LPA induzida por AO.

\subsection{Método de indução da LPA por AO}

O modelo AO foi escolhido por reproduzir as características básicas da LPA, causando lesão pulmonar inflamatória irregular precoce e, potencialmente reversível, alterações da permeabilidade com comprometimento das trocas gasosas e da mecânica pulmonar. Uma das principais vantagens deste modelo é a sua reprodutibilidade. A administração da mesma dose de AO, pela mesma via de diferentes animais, leva a lesão pulmonar razoavelmente reprodutível (MATUTE-BELLO, FREVERT e MARTIN, 2008).

Apesar da lesão em modelos animais apresentar características patológicas similares as da LPA/SDRA, a etiologia pode ser diferente em humanos. Assim, o modelo AO tem sido amplamente utilizado para estudar as consequências da lesão pulmonar e avaliar novas estratégias de tratamento. No entanto, por causa da sua etiologia diferente, os resultados devem ser cautelosamente extrapolados para LPA/SDRA em humanos (WANG, BODENSTEIN e MARKSTALLER, 2008).

O animal de experimentação inicialmente escolhido foi o coelho, tornando extremamente frustrante a primeira etapa do projeto pela frequente ocorrência de coelhos com pneumonia. Como os dados encontrados no Grupo Controle indicaram que esses animais possuíam algum tipo de alteração pulmonar prévia, não se conseguiu caracterizar com segurança a LPA no modelo experimental proposto (dados não apresentados). Diante do exposto, optou-se por mudar o modelo experimental, passando a utilizar ratos Wistar.

Esse modelo mostrou-se muito bom tornando possível a realização de todas as etapas experimentais do projeto, cujos achados principais foram: 1) Não se observou hipoxemia grave em 4h de LPA; 2) O grupo pré-tratamento apresentou diferença significativa com menor quantificação de exsudato proteico; 3) Embora não estatisticamente significativos, observaram-se valores menores da relação PU/PS e do NO tecidual nos grupos que foram tratados com AM; 4) O exame macroscópico dos pulmões não tratados revelou maior comprometimento (hepatização, edema), confirmado pelo exame histológico, que evidencia 
áreas de congestão, edema, exsudato intra-alveolar proteico, áreas de hemorragia e infiltrado inflamatório neutrofílico, além de algumas áreas de necrose septal.

O AM diminuiu a permeabilidade pulmonar quando administrado de maneira precoce na LPA induzida por AO. Entretanto, chamou atenção os focos de necrose septal ainda presentes sugerindo a existência de um efeito mecânico além do químico preconizado para o AO.

\subsection{Trocas gasosas}

Perturbação nas trocas gasosas e aumento da permeabilidade pulmonar são algumas das características mais importantes de LPA. O tratamento com AM melhora o tônus vascular pulmonar após LPA por AO, e como consequência, melhora as trocas gasosas (LEEMAN et al., 1993) $\mathrm{O}$ parâmetro adotado na presente investigação foi a relação $\mathrm{PaO}_{2} / \mathrm{FiO}_{2}$ em rato respirando espontaneamente.

A oxigenação sanguínea é fortemente afetada na LPA por alterações da relação ventilação/perfusão. Ensaios experimentais em ratos mostraram a ocorrência de hipoxemia em diferentes tempos após a indução da lesão (SUN et al., 2009; WEI et al., 2011; YAN et al., 2012). No presente estudo, não foi encontrado hipoxemia grave após 4 h de LPA com a dose de $70 \mathrm{mg} / \mathrm{kg}$ de AO.

Gaio et al (2009) estudaram a estabilidade hemodinâmica, mecânica respiratória e de troca gasosa na LPA induzida por AO e concluíram que as variáveis de trocas gasosas e da mecânica respiratória se estabilizam precocemente, nas primeiras $2 \mathrm{~h}$ pós-lesão. Diante dos presentes achados, é possível que a variável tempo, para a dose de AO utilizada, possa indicar um viés para os resultados esperados com relação ao índice de oxigenação .

DiRocco et al (2006) induziram LPA em ratos com quatro métodos diferentes, dentre eles AO, porém, o AO foi administrado continuamente até que se atingisse a relação $\mathrm{PaO}_{2} / \mathrm{FiO}_{2}<300$, o que foi obtido por volta de 60 min após o início da indução da lesão. Entretanto, em algumas pesquisas publicadas, encontraram-se relatos de que o fluxo sanguíneo pulmonar se redistribui para regiões pulmonares preservadas, ou seja, sem a presença de lesão endotelial. Sendo assim, mantém-se um padrão relativamente normal de oxigenação, minimizando a queda da $\mathrm{PaO}_{2}$ (STEPHENSON et al., 1992; SCHUSTER et al., 1996; GUST et al., 1999).

Imagens macroscópicas dos pulmões mostraram áreas heterogêneas de lesão no tecido, principalmente nos grupos que receberam tratamento com AM. Esses resultados vão ao encontro de estudos que também observaram uma lesão heterogênea causada pelo AO 
(YANG et al., 2014). Essa observação pode sugerir que as áreas preservadas podem ter conseguido manter uma adequada ventilação/perfusão, deixando os índices de oxigenação acima do valor indicativo de lesão.

Alguns autores relatam que para obter uma lesão mais uniforme, deve-se repetir a dose de AO por mais vezes enquanto o animal é colocado em diferentes posições (supino , lateral direito e lateral esquerdo), o que não foi realizado no presente estudo (BALLARDCROFT et al., 2012).

Além dos fatores acima mencionados, sabe-se que a relação $\mathrm{PaO}_{2} / \mathrm{FiO}_{2}$ não pode distinguir entre hipoventilação e desbalanço da relação V/Q. Modelos matemáticos demonstram que a relação $\mathrm{PaO}_{2} / \mathrm{FiO}_{2}$ é dependente da pressão barométrica, e não é confiável a menos que $\mathrm{FiO}_{2}>0,5$ ou $\mathrm{PaO}_{2}<100$. Isso significa, em outras palavras, que a relação $\mathrm{PaO}_{2} / \mathrm{FiO}_{2}$ tem uma dependência estrita da $\mathrm{FiO}_{2}$, cujo valor e constância são, em geral, obtidos com auxílio de suporte ventilatório. O fato dos ratos terem sido mantidos em respiração espontânea (suposta $\mathrm{FiO}_{2}=0,21,<0,5$ ), com certeza interferiu na avaliação desse parâmetro, pois se observou uma extrema variabilidade do ritmo respiratório dos animais anestesiados (KARBING et al., 2007).

\subsection{Permeabilidade capilar pulmonar}

Além do estudo histológico, a presente investigação adotou dois métodos conhecidos e adotados na literatura: a relação PU/PS e a dosagem da concentração de proteínas no lavado bronco-alveolar, amplamente utilizados como indicadores da LPA (CHEN et al., 2008; GUO et al., 2011). Embora seja uma metodologia simples, segundo Zhi-Guang (2013), a medida da relação do PU/PS no pulmão reflete a integridade do epitélio alveolar que se encontra destruído na LPA induzida por paraquat, isquemia-reperfusão (WEINBROUM, 2009), endotoxina (EVGENOV et al., 2002) e por AO (CHEN et al., 2008; GUO et al., 2011; TIAN et al., 2013). No presente estudo observaram-se aumentos da relação PU/PS e da concentração de proteínas no lavado bronco-alveolar, confirmando a perda da integridade da membrana alvéolo-capilar.

Em estudos de lesão aguda em pulmão de ruminantes, o AM atenuou em 50\% o edema e a hipertensão pulmonar mediada pela administração de endotoxina. Porém, os efeitos benéficos do AM somente ocorreram em uma fase precoce dos experimentos, exaurindo-se após 2h, com aumento paralelo da hipertensão pulmonar (EVORA, CELOTTO e CAPELLINI, 2011). Da mesma forma, Leeman et al (1993) relatam aumento do tônus vascular pulmonar, melhora da troca gasosa e diminuição do edema causado por AO após 
administração de AM.

Os dados do presente estudo corroboram com esses achados. O AM se mostrou eficaz na prevenção da LPA, por sua ação de preservação da permeabilidade capilar pulmonar. Esse efeito foi mais bem observado na administração precoce do AM, como prétratamento, quando se observaram valores significativos na redução do número de proteínas no lavado bronco-alveolar. Esses achados vão de encontro com estudos realizados em ovelhas, onde a infusão precoce de AM atenua a lesão pulmonar através da diminuição do edema, da permeabilidade e da pressão capilar pulmonar (EVGENOV, SAGER e BJERTNAES ,2001; EVGENOV, SVEINBJORNSSON e BJERTNAES, 2001).

Estudos analisando choque séptico induzido por endotoxinas em ovelhas mostram a diminuição da GMPc e NOx em níveis plasmáticos após o tratamento com AM. Como consequência, o AM aumenta a resistência vascular sistêmica, diminui a permeabilidade capilar com redução do edema pulmonar e dos sinais morfológicos da LPA. Segundo Evgenov et al (2002), o AM pode restaurar o bombeamento da linfa do pulmão, provavelmente pela redução da GMPc nos vasos linfáticos. Além disso, restaura transitoriamente a pressão arterial média e melhora a função do miocárdio (EVGENOV, SAGER e BJERTNAES, 2001). Trabalhos realizados in vitro utilizando aortas de ratos relatam uma completa restauração da hiporreatividade vascular através da inibição da GCs e consequente redução de GMPc (WU, CHEN e YEN, 1998).

Embora os dados não tenham sido estatisticamente significativos, após a administração de AM, tanto profilático como tratamento, verificaram-se nítida diminuição do edema e do exudato proteico. Atribui-se essas respostas à inibição da GCs pelo AM, bloqueando a via NO-GMPc.

\subsection{Nitrito/Nitrato (NOx) plasmático e tecidual}

O NO tem a capacidade de regular o tônus vascular adaptando o fluxo de sangue para atender a demanda metabólica dos tecidos. A sua produção é aumentada na presença de inflamação. Estudo realizado em cães relata um aumento significativo do NO tanto plasmático como tecidual após LPA por AO (LAI, CAI e GUO, 2010). No presente estudo, apesar de não ser encontrado dados estatisticamente significativos, o grupo de lesão apresentou valores mais elevados de NOx tecidual comparado aos controles. É possível que esse aumento fosse maior após 6h, como citado nos resultados de Lai et al (2010), porém o tecido pulmonar foi coletado 4h após a lesão.

O método de dosagem do NOx plasmático pelo método da quimioluminescência, ao 
contrário da dosagem tecidual, tem sido causa de constante frustração nos estudos realizados no Laboratório de Função Endotelial do Departamento de Cirurgia e Anatomia da FMRPUSP, quase sempre apresentando valores dentro da normalidade independente de variados protocolos experimentais. No presente estudo, além de não ter havido diferença estatisticamente significativa em relação aos níveis de NO plasmático entre os grupos estudados, esses níveis foram, em valores absolutos, muito semelhantes entre eles.

Pesquisas realizadas em ovelhas com endotoxemia e em humanos em choque séptico, o NOx plasmático circulante tem apresentado aumento de duas a sete vezes comparado aos controles saudáveis. Entretanto, Evgenov et al (2001b) encontraram um aumento do NOx plasmático de $40 \%$ em ovelhas endotoxemicas, provavelmente refletindo uma modesta ativação da iNOS. A inalação ou a infusão contínua de endotoxina apresenta um pico de NOx plasmático após $18 \mathrm{~h}$.

Segundo Ballard-Croft et al (2012), a indução de LPA por AO não é um bom modelo para estudar fisiopatologia inflamatória, pois a inflamação pode não ser necessária para causar a lesão pulmonar. A iNOS expressa-se em resposta a estímulos pró-inflamatórios em numerosas células e resulta na síntese de grande quantidade de NO em média $6 \mathrm{~h}$ depois da exposição ao agente inflamatório (EVORA, CELOTTO e CAPELLINI, 2011). No presente estudo, as coletas foram realizadas 4 h após a exposição ao AO, podendo ser esse um fator por não se observar um aumento do NOx.

Evgenov et al (2001a) analisaram os efeitos do AM em animais com sepse induzida por LPS e observaram uma maior redução do GMPc do que do NOx plasmático. Atribuíram esse fato a maior capacidade do AM em inibir a GCs do que a NOS in vivo. Os resultados apresentados na presente investigação mostram uma diminuição do NOx tecidual nos grupos tratados com AM comparados ao grupo de lesão, porém sem diferença significativa.

Segundo Fernandes et al (2006), existe uma possível "janela de oportunidade" para efetividade do AM. Esse conceito foi estabelecido experimentalmente em ratos, utilizando um modelo de sepse, evidenciando três janelas de 8h de atividade da GC. Nas primeiras 8h, há aumento da NOS e uma regulação positiva GC. Nas oito horas seguintes, há uma ausência de expressão do GC e uma regulação negativa da NOS. Na terceira janela de 8h, há novamente um aumento da expressão de GC e NOS. Esses dados ressaltam dois aspectos fundamentais práticos e educativos: 1) Usar o tratamento com AM considerando a janela de oportunidade, e, 2) A necessidade da criação desta janela, em seres humanos, talvez escolhendo cGMP como biomarcador, uma vez que a tentativa de usar NOx, medido por quimiluminescência, têm sido frustrante em alguns trabalhos realizados pelo grupo (EVORA e VIARO, 2006; 
EVORA et al., 2007; VIARO et al., 2008).

A utilização do AM é dependente do tempo, devendo ser utilizado precocemente (primeira janela), pois na segunda janela a GC tem baixa expressão e na terceira janela consegue-se uma tardia melhora das condições hemodinâmicas, porém em uma situação metabólica grave. Embora não demonstrado na presente investigação, o fato da utilização precoce do AM ser mais eficiente sugere a existência, também, de uma "janela de oportunidade" terapêutica para a circulação pulmonar.

Outra hipótese seria a realização da análise específica da iNOS, o que não foi realizada neste trabalho, podendo encontrar algumas respostas mais específicas com relação às alterações do NO plasmático e tecidual e da resposta obtida pelo tratamento com AM. Yeh et al (2009) e Yeh et al (2008) realizaram estudos utilizando PCR em tempo real e Western blot para analisar as expressões de RNAm e de proteínas da iNOS plasmático após LPA por isquemia/reperfusão e AO e observaram um aumento nas expressões de RNAm e proteínas da iNOS após $6 \mathrm{~h}$.

Acreditamos também que as diferenças encontradas nos trabalhos com relação às espécies e aos modelos utilizados para indução de LPA poderiam explicar as discrepâncias entre os estudos.

\subsection{Achados macroscópicos e histológicos}

O exame macroscópico dos pulmões não tratados com AM revelou maior comprometimento (hepatização, edema), confirmado pelo exame histológico. Esses dados corroboram com as descrições macroscópicas realizadas por Miyazawa et a (1981), onde os autores observaram, após LPA por AO, os pulmões edemaciados, 2-3 vezes mais pesado do que seu peso normal, e as superfícies afetadas por hemorragia. Relataram, ainda, a presença de moderada a grandes quantidades de espuma sangrenta na traqueia e brônquios principais, o que também foi observado na presente investigação.

Derks e Jakobovitz - Derks (1977) realizaram uma descrição detalhada das alterações morfológicas pulmonares encontradas após a administração de AO em cães. Seis a doze horas após a injeção AO, os pulmões apresentaram inundação alveolar, congestão capilar, hemorragia e necrose do septo. Em outro estudo realizado em suínos, após 5 horas de infusão de AO, as mesmas características foram observadas (WANG et al., 2010). Da mesma forma, os achados desse trabalho revelaram as mesmas alterações histológicas em ratos.

Os dados da microscopia também sugerem que a principal ação do AM parece relacionada à diminuição da congestão, edema intra-alveolar, extravasamento proteico 
(exsudato proteico intra-alveolar indicando lesão capilar) e áreas de hemorragia. Essa ação de diminuição da permeabilidade é evidente quando o AM é infundido precocemente.

Da mesma forma, Greca et al (2004) observaram redução do edema intersticial e um menor índice de lesão pulmonar, com menos infiltrado de neutrófilos na análise histológica, após administração de AM precoce.

Tian et al (2013) observaram alterações pulmonares como edema, infiltrado de neutrófilos, hemorragia, colapso alveolar difuso e espessamento de septo alveolar em ratos com LPA induzida por paraquat. Iniciaram o tratamento com AM após $2 \mathrm{~h}$ de lesão, e após $24 \mathrm{~h}$, observaram que essas alterações foram bem reduzidas.

Os dados histológicos desse trabalho mostram que o AM reduz o edema principalmente quando administrado precocemente, entretanto, não consegue evitar áreas de necrose septal. Supõe-se que a sua ação limita-se ao efeito na permeabilidade capilar sendo inefetivo perante os demais mecanismos de lesão provocados pelo $\mathrm{AO}$, dentre eles, o efeito tóxico (QUELUZ, DEFAVERI e EL--FAKHOURI, 1997) e a ação direta nas células alveolares e endoteliais (PELTIER, 1956; WANG, BODENSTEIN e MARKSTALLER, 2008).

Essa pesquisa não estudou a gênese e nem os possíveis efeitos do $\mathrm{AM}$ nos focos de necrose. Queluz et al (2007) relataram que embora o padrão morfológico da lesão seja isquêmico, acredita-se que ela seja decorrente de pelo menos dois fatores: os fenômenos embólicos, mecânicos e reflexos, e a ação tóxica direta do AO. 


\section{CONCLUSÃO}

Os dados obtidos nesse trabalho sugerem que o AM diminui a permeabilidade pulmonar quando administrado de maneira precoce amenizando os danos causados pela LPA induzida por $\mathrm{AO}$. 


\section{REFERÊNCIAS BIBLIOGRÁFICAS}

Amato, M. B. P., et al. III Consenso Brasileiro de Ventilação Mecânica: Ventilação mecânica na Lesão Pulmonar Aguda (LPA)/ Síndrome do Desconforto Respiratório Agudo (SDRA). J Bras Pneumol, v.33, n.2, p.119-127. 2007.

Ando, K., et al. The effect of comorbidity on the prognosis of acute lung injury and acute respiratory distress syndrome. Intern Med, v.51, n.14, p.1835-40. 2012.

Andrade, J. C. S., et al. Utilização do azul de metileno no tratamento da síndrome vasoplégica após cirurgia cardíaca. Rev Bras Cir Cardiovasc, v.11(2), p.107-14. 1996.

Antoniazzi, P., et al. Síndrome da Angústia Respiratória Aguda (SARA). Medicina, Ribeirão Preto, v.31, p.493-506. 1998.

Atalay, C., et al. The efficacy of spironolactone in the treatment of acute respiratory distress syndrome-induced rats. Singapore Med J, v.51, n.6, Jun, p.501-5. 2010.

Baldo, C. F. Efeitos clínicos da inibição do sistema sGC-cGMP pelo azul de metileno no choque decorrente da pancreatite em porcos. Faculdade de Medicina de Ribeirão Preto, Faculdade de Medicina de Ribeirão Preto da Universidade de São Paulo, Ribeirão Preto, 2009. 279 p.

Baldo, C. F., et al. Guanylate cyclase inhibition by methylene blue in circulatory shock caused by acute necrotizing pancreatitis: a word of caution based on a porcine model. Rev Col Bras Cir, v.40, n.6, Dec, p.480-489. 2013.

Ballard-Croft, C., et al. Large-animal models of acute respiratory distress syndrome. Ann Thorac Surg, v.93, n.4, Apr, p.1331-9. 2012.

Bao, Z., et al. Humanized monoclonal antibody against the chemokine CXCL-8 (IL-8) effectively prevents acute lung injury. Int Immunopharmacol, v.10, n.2, Feb, p.259-63. 2010.

Barnes, P. J. e M. G. Belvisi. Nitric oxide and lung disease. Thorax, v.48, n.10, Oct, p.103443. 1993.

Basile Filho, A. e A. Capone Neto. Síndrome da Angústia Respiratória do Adulto: Primeira Parte. Rev Bras Anest, v.38, n.6, p.431-443. 1988.

Bernard, G. R. Acute respiratory distress syndrome: a historical perspective. Am J Respir Crit Care Med, v.172, n.7, Oct 1, p.798-806. 2005.

Bernard, G. R., et al. The American-European Consensus Conference on ARDS. Definitions, mechanisms, relevant outcomes, and clinical trial coordination. Am J Respir Crit Care Med, v.149, n.3 Pt 1, Mar, p.818-24. 1994.

Bersten, A. D., et al. Incidence and mortality of acute lung injury and the acute respiratory distress syndrome in three Australian States. Am J Respir Crit Care Med, v.165, n.4, Feb 15, p.443-8. 2002. 
Bertoni, J. A. Papel da Heme Oxigenase 1 na modulação da inflamação pulmonar causada pela isquemia e reperfusão intestinal em ratos. Departamento de Farmacologia do Instituto de Ciências Biomédicas da Universidade de São Paulo, Universidade de São Paulo, São Paulo, 2012.

Blatyta, P. F., et al. The impact of policies to restrict the use of plasma containing products and apheresis platelets from female donors to mitigate transfusion related acute lung injury (TRALI) in Brazil. Transfus Apher Sci, v.48, n.1, Feb, p.15-20. 2013.

Boumgarten, R., E. M. Dalmarco e C. L. Guimarães. Inibição do edema pulmonar em camundongos por bloqueadores das fosfodiesterases. v.3, n.14, p.37-41. 2008.

Brauer, R. B., et al. Endotoxin-induced lung inflammation is independent of the complement membrane attack complex. Infect Immun, v.68, n.3, Mar, p.1626-32. 2000.

Brigham, K. L. e B. Meyrick. Endotoxin and lung injury. Am Rev Respir Dis, v.133, n.5, May, p.913-27. 1986.

Capelozzi, V. L. Difficulties to interpret biopsies in diffuse lung diseases. J Pneumol, v.24 (1), p.30-42. 1998.

Cerqueira, N. F. e W. B. Yoshida. Óxido nítrico: revisão. Acta Cir Bras [serial online], v.17, n.6, Nov-Dez. 2002.

Chen, C. C., et al. Shortening of cardiac action potentials in endotoxic shock in guinea pigs is caused by an increase in nitric oxide activity and activation of the adenosine triphosphatesensitive potassium channel. Crit Care Med, v.28, n.6, Jun, p.1713-20. 2000.

Chen, H. I., et al. Protective effects of propofol on acute lung injury induced by oleic acid in conscious rats. Crit Care Med, v.36, n.4, Apr, p.1214-21. 2008.

Cribbs, S. K., M. A. Matthay e G. S. Martin. Stem cells in sepsis and acute lung injury. Crit Care Med, v.38, n.12, Dec, p.2379-85. 2010.

Crocker, G. H. e J. H. Jones. Effects of oleic acid-induced lung injury on oxygen transport and aerobic capacity. Respir Physiol Neurobiol, Mar 1. 2014.

Da Cunha, A. A., et al. Treatment with N-methyl-d-aspartate receptor antagonist (MK-801) protects against oxidative stress in lipopolysaccharide-induced acute lung injury in the rat. Int Immunopharmacol, Feb 3. 2011.

Derks, C. M. e D. Jacobovitz-Derks. Embolic pneumopathy induced by oleic acid. A systematic morphologic study. Am J Pathol, v.87, n.1, Apr, p.143-58. 1977.

Diaz, A. D. P. U. Aspectos clínico-laboratoriais do uso do azul de metileno na obstrução experimental do jejuno em equinosexpostos ao lipopolissacarídeo (LPS). Faculdade de Ciências Agrárias e Veterinária, Unesp, Jaboticabal, 2009. 80 p.

Dirocco, J. D., et al. Dynamic alveolar mechanics in four models of lung injury. Intensive 
Care Med, v.32, n.1, Jan, p.140-8. 2006.

Doi, K., et al. Lung injury following acute kidney injury: kidney-lung crosstalk. Clin Exp Nephrol, v.15, n.4, Aug, p.464-70. 2011.

Dong, H. Y., et al. Leptin attenuates lipopolysaccharide or oleic acid-induced acute lung injury in mice. Am J Respir Cell Mol Biol, v.49, n.6, Dec, p.1057-63. 2013.

Duluc, L. e B. Wojciak-Stothard. Rho GTPases in the regulation of pulmonary vascular barrier function. Cell Tissue Res, Mar 6. 2014.

Evgenov, O. V., et al. Methylene blue reduces pulmonary oedema and cyclo-oxygenase products in endotoxaemic sheep. Eur Respir J, v.20, n.4, Oct, p.957-64. 2002.

Evgenov, O. V., G. Sager e L. J. Bjertnaes. Methylene blue reduces lung fluid filtration during the early phase of endotoxemia in awake sheep. Crit Care Med, v.29, n.2, Feb, p.3749. 2001.

Evgenov, O. V., B. Sveinbjornsson e L. J. Bjertnaes. Continuously infused methylene blue modulates the early cardiopulmonary response to endotoxin in awake sheep. Acta Anaesthesiol Scand, v.45, n.10, Nov, p.1246-54. 2001.

Evora, P. R. e A. J. Rodrigues. Methylene blue revised. J Thorac Cardiovasc Surg, v.131, n.1, Jan, p.250-1; author reply 251. 2006.

Evora, P. R., et al. Is the cyclic GMP system underestimated by intensive care and emergency teams? Med Hypotheses, v.69, n.3, p.564-7. 2007.

Evora, P. R. e F. Viaro. The guanylyl cyclase inhibition by MB as vasoplegic circulatory shock therapeutical target. Curr Drug Targets, v.7, n.9, Sep, p.1195-204. 2006.

Evora, P. R. B., A. C. Celotto e V. K. Capellini. Disfunção Entotelial Vasoplégica e Choque Circulatório. São Paulo: Atheneu. 2011. 85 p.

Fang, X., C. Bai e X. Wang. Bioinformatics insights into acute lung injury/acute respiratory distress syndrome. Clin Transl Med, v.1, n.1, p.9. 2012.

Fernandes, D. Dinâmica da guanilato ciclase solúvel na sepse: uma janela de oportunidade. Curso de Pós-Graduação em Farmacologia, Universidade Federal de Santa Catarina, Florianópolis, 2006. 113 p.

Fernandes, D., et al. Nitric oxide-dependent reduction in soluble guanylate cyclase functionality accounts for early lipopolysaccharide-induced changes in vascular reactivity. Mol Pharmacol, v.69, n.3, Mar, p.983-90. 2006.

Fialkow, L., et al. Acute lung injury and acute respiratory distress syndrome at the intensive care unit of a general university hospital in Brazil. An epidemiological study using the American-European Consensus Criteria. Intensive Care Med, v.28, n.11, Nov, p.1644-8. 2002. 
Filomeno, L. T. B., et al. Fat Embolism: a review for current orthopaedics practice. Acta Ortop Bras, v.13(4). 2005.

Gaio, E., et al. Stability of the animal model of oleic acid-induced acute lung injury. J Bras Pneumol, v.35, n.8, Aug, p.759-66. 2009.

Galhardo, F. P. L. e J. A. B. Martinez. Síndrome do Desconforto Respiratório Agudo. Medicina, Ribeirão Preto, v.36, abril./dez., p.248-256. 2003.

Goebel, U., et al. Flow-controlled expiration: a novel ventilation mode to attenuate experimental porcine lung injury. Br J Anaesth, Apr 2. 2014.

Greca, F. H., et al. The role of the methylene blue as a lung protector after intestinal ischemia and reperfusion. Acta Cir Bras, v.19(4), Jul./Ag. 2004.

Grigoriu, R. G., R. Balan e V. Rusu. [Animal model of acute respiratory distress syndrome]. Rev Med Chir Soc Med Nat Iasi, v.112, n.1, Jan-Mar, p.174-82. 2008.

Guo, Q., et al. VEGF, Bcl-2 and Bad regulated by angiopoietin-1 in oleic acid induced acute lung injury. Biochem Biophys Res Commun, v.413, n.4, Oct 7, p.630-6. 2011.

Gust, R., et al. Role of cyclooxygenase-2 in oleic acid-induced acute lung injury. Am J Respir Crit Care Med, v.160, n.4, Oct, p.1165-70. 1999.

Hall, N. G., et al. Bactericidal function of alveolar macrophages in mechanically ventilated rabbits. Am J Respir Cell Mol Biol, v.34, n.6, Jun, p.719-26. 2006.

Hataishi, R., et al. Inhaled nitric oxide decreases infarction size and improves left ventricular function in a murine model of myocardial ischemia-reperfusion injury. Am J Physiol Heart Circ Physiol, v.291, n.1, Jul, p.H379-84. 2006.

Karbing, D. S., et al. Variation in the $\mathrm{PaO} 2 / \mathrm{FiO} 2$ ratio with $\mathrm{FiO} 2$ : mathematical and experimental description, and clinical relevance. Crit Care, v.11, n.6, p.R118. 2007.

Kirov, M. Y., O. V. Evgenov e L. J. Bjertnaes. Combination of intravenously infused methylene blue and inhaled nitric oxide ameliorates endotoxin-induced lung injury in awake sheep. Crit Care Med, v.31, n.1, Jan, p.179-86. 2003.

Knowles, R. G. e S. Moncada. Nitric oxide synthases in mammals. Biochem J, v.298 ( Pt 2), Mar 1, p.249-58. 1994.

Kuwabara, K., et al. Effect of methylprednisolone on phospholipase A(2) activity and lung surfactant degradation in acute lung injury in rabbits. Eur J Pharmacol, v.433, n.2-3, Dec 21, p.209-16. 2001.

Lai, T. S., S. X. Cai e Z. H. Guo. Serum and lung endothelin-1 increased in a canine model of ventilator-induced lung injury. Chin Med J (Engl), v.123, n.8, Apr 20, p.1021-7. 2010.

Leeman, M., et al. Is nitric oxide released in oleic acid lung injury? J Appl Physiol (1985), v.74, n.2, Feb, p.650-4. 1993. 
Levitzky, M. G. Fisiologia Pulmonar. Rio de Janeiro: McGraw-Hill. 2009. 280 p.

Liu, A. J., et al. Effect of oleic acid-induced acute lung injury and conventional mechanical ventilation on renal function in piglets. Chin Med J (Engl), v.126, n.13, Jul, p.2530-5. 2013.

Lo, J. C., M. A. Darracq e R. F. Clark. A Review of Methylene Blue Treatment for Cardiovascular Collapse. J Emerg Med, Feb 6. 2014.

Matthay, M. A. Alveolar fluid clearance in patients with ARDS: does it make a difference? Chest, v.122, n.6 Suppl, Dec, p.340S-343S. 2002.

Matthay, M. A. e R. L. Zemans. The acute respiratory distress syndrome: pathogenesis and treatment. Annu Rev Pathol, v.6, Feb 28, p.147-63. 2011.

Matute-Bello, G., C. W. Frevert e T. R. Martin. Animal models of acute lung injury. Am J Physiol Lung Cell Mol Physiol, v.295, n.3, Sep, p.L379-99. 2008.

Mayer, B., F. Brunner e K. Schmidt. Inhibition of nitric oxide synthesis by methylene blue. Biochem Pharmacol, v.45, n.2, Jan 26, p.367-74. 1993a.

Mayer, B., F. Brunner e K. Schmidt.. Novel actions of methylene blue. Eur Heart J, v.14 Suppl I, Nov, p.22-6. 1993b.

Miyazawa, T., et al. Ultrastructural study on the alveolar-capillary injury with pulmonary edema induced by oleic acid in dogs. Hiroshima J Med Sci, v.30, n.3, Sep, p.183-90. 1981.

Peltier, L. F. Fat embolism. III. The toxic properties of neutral fat and free fatty acids. Surgery, v.40, n.4, Oct, p.665-70. 1956.

Pinheiro, B. V., et al. Accuracy of clinical diagnosis of acute respiratory distress syndrome in comparison with autopsy findings. J Bras Pneumol, v.33, n.4, Aug, p.423-8. 2007.

Queluz, T. H. A. T., J. Defaveri e S. El--Fakhouri. Alterações Morfológicas Induzidas Pelo Ácido Oléico em Pulmões de Ratos. J Pneumol, v.23, n.5, p.245-251. 1997.

Rincon, F., et al. Impact of acute lung injury and acute respiratory distress syndrome after traumatic brain injury in the United States. Neurosurgery, v.71, n.4, Oct, p.795-803. 2012.

Ritter, C., et al. Effects of $\mathrm{N}$-acetylcysteine plus deferoxamine in lipopolysaccharide-induced acute lung injury in the rat. Crit Care Med, v.34, n.2, Feb, p.471-7. 2006.

Rodrigues, D. Ventilação Mecânica na Síndrome da Angústia Respiratória Aguda (SARA). Salgado Filho, São Paulo, 2003. 48 p.

Samano, M. N. Estudo dos efeitos da pneumonectomia esquerda sobre o pulmão remanescente de ratos: avaliação das alterações histológicas e funcionais agudas. Faculdade de Medicina da Universidade de São Paulo, São Paulo, 2008. 114 p.

Scanlan, C., J. Wilkins e J. Stoller. Fundamentos da Terapia Respiratória de Egan. São Paulo: 
Manole. 2000. 1291 p.

Schirmer, R. H., et al. "Lest we forget you - methylene blue ..." Neurobiol Aging, Feb 11. 2011.

Schuster, D. P., et al. Effect of eicosanoid inhibition on the development of pulmonary edema after acute lung injury. J Appl Physiol (1985), v.80, n.3, Mar, p.915-23. 1996.

Stephenson, A. H., et al. Eicosanoid balance and perfusion redistribution of oleic acidinduced acute lung injury. J Appl Physiol (1985), v.73, n.5, Nov, p.2126-34. 1992.

Sun, Y., et al. Aerosolised surfactant generated by a novel noninvasive apparatus reduced acute lung injury in rats. Crit Care, v.13, n.2, p.R31. 2009.

Tian, Z. G., et al. Methylene blue protects against paraquat-induced acute lung injury in rats. Int Immunopharmacol, v.17, n.2, Jul 8, p.309-313. 2013.

Toya, S. P. e A. B. Malik. Role of endothelial injury in disease mechanisms and contribution of progenitor cells in mediating endothelial repair. Immunobiology, v.217, n.5, May, p.56980. 2012.

Van Diepen, S., et al. A case of acute respiratory distress syndrome responsive to methylene blue during a carcinoid crisis. Can J Anaesth, v.60, n.11, Nov, p.1085-8. 2013.

Viaro, F., et al. Plasma nitrate/nitrite (NOx) is not a useful biomarker to predict inherent cardiopulmonary bypass inflammatory response. J Card Surg, v.23, n.4, Jul-Aug, p.336-8. 2008.

Villar, J., J. Blanco e R. M. Kacmarek. Acute respiratory distress syndrome definition: do we need a change? Curr Opin Crit Care, v.17, n.1, Feb, p.13-7. 2011.

Voelkel, N. F. e S. Rounds. The Pulmonary Endothelium

Function in health and disease. USA: John Wiley \& Sons, Ltd. 2009

Volpe, B. T., W. Lin e R. S. Thrall. Effect of intratracheal dexamethasone on oleic acidinduced lung injury in the rat. Chest, v.106, n.2, Aug, p.583-7. 1994.

Wang, H. M., et al. Ventilator-associated lung injury superposed to oleic acid infusion or surfactant depletion: histopathological characteristics of two porcine models of acute lung injury. Eur Surg Res, v.45, n.3-4, p.121-33. 2010.

Wang, H. M., M. Bodenstein e K. Markstaller. Overview of the pathology of three widely used animal models of acute lung injury. Eur Surg Res, v.40, n.4, p.305-16. 2008.

Ware, L. B. e M. A. Matthay. The acute respiratory distress syndrome. N Engl J Med, v.342, n.18, May 4, p.1334-49. 2000.

Ware, L. B. e M. A. Matthay. Alveolar fluid clearance is impaired in the majority of patients with acute lung injury and the acute respiratory distress syndrome. Am J Respir Crit Care Med, v.163, n.6, May, p.1376-83. 2001. 
Wei, T., et al. The impact of sodium aescinate on acute lung injury induced by oleic acid in rats. Exp Lung Res, v.37, n.10, Dec, p.585-99. 2011.

Weinbroum, A. A. Methylene blue attenuates pancreas ischemia-reperfusion (IR)-induced lung injury: a dose response study in a rat model. J Gastrointest Surg, v.13, n.9, Sep, p.168391. 2009.

West, J. B. Fisiologia respiratória moderna. São Paulo: Manole . 1990

Wiedemann, H. P., M. A. Matthay e C. N. Gillis. Pulmonary endothelial cell injury and altered lung metabolic function. Early detection of the adult respiratory distress syndrome and possible functional significance. Clin Chest Med, v.11, n.4, Dec, p.723-36. 1990.

Wu, C. C., S. J. Chen e M. H. Yen. Nitric oxide-independent activation of soluble guanylyl cyclase contributes to endotoxin shock in rats. Am J Physiol, v.275, n.4 Pt 2, Oct, p.H114857. 1998.

Yan, Y. M., et al. Therapeutic effects of inhaling aerosolized surfactant alone or with dexamethasone generated by a novel noninvasive apparatus on acute lung injury in rats. $\mathbf{J}$ Trauma Acute Care Surg, v.73, n.5, Nov, p.1114-20. 2012.

Yang, Y., et al. Effects of recruitment maneuvers with PEEP on lung volume distribution in canine models of direct and indirect lung injury. Mol Biol Rep, v.41, n.3, Mar, p.1325-33. 2014.

Yeh, D. Y., et al. Inducible nitric oxide synthase expressions in different lung injury models and the protective effect of aminoguanidine. Transplant Proc, v.40, n.7, Sep, p.2178-81. 2008.

Zhu, G. F., et al. Combined surfactant therapy and inhaled nitric oxide in rabbits with oleic acid-induced acute respiratory distress syndrome. Am J Respir Crit Care Med, v.158, n.2, Aug, p.437-43. 1998. 


\section{APÊNDICES}

Apêndice 1.

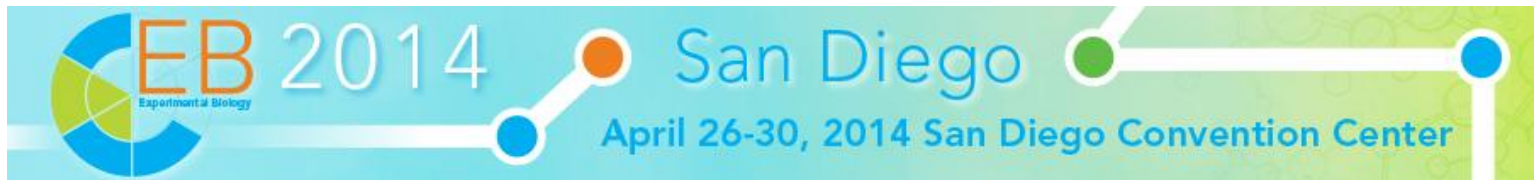

Dear Ana Paula Silveira

\section{EXPERIMENTAL BIOLOGY 2014 ABSTRACT CONFIRMATION OF POSTER PRESENTATION - APS San Diego Convention Center - 111 W. Harbor Drive, San Diego, CA 92101}

The following will confirm the date, time, and location of your poster presentation. Please advise co-authors of the time and place of the presentation as they will not receive a separate notification. Only the sponsor of the abstract will receive a copy of this email. Please review all the information in this memo carefully. This will be the only correspondence you will receive.

Your abstract has been programmed in the following poster session.

\section{POSTER PRESENTATION Date, Time, and Location}

Abstract Number: 3489

Abstract Title: Methylene blue protects against oleic acid-induced acute lung injury in rats

Presenting Author: Ana Paula Silveira

Poster Session Title: Lung Physiology: Fluid Balance

Day of Presentation: Sunday, April 27, 2014

Program Number: 718.2

Poster Board Number: A570

Authors must be present at their posters from: 4/27/2014 12:45 - 4/27/2014 15:00

Location: San Diego Convention Center, Exhibit Halls A-D 
Apêndice 2.

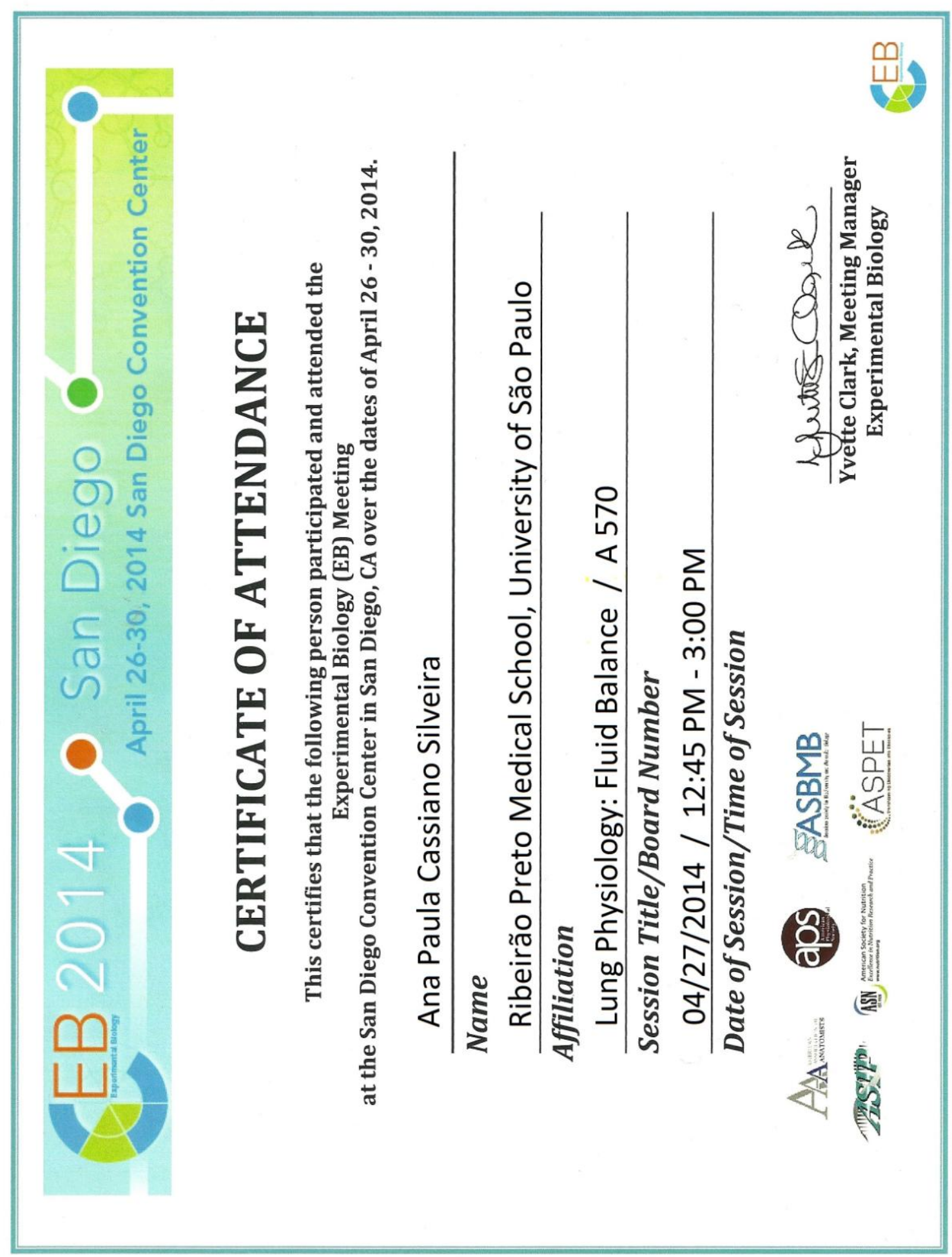




\section{Apêndico 3.}
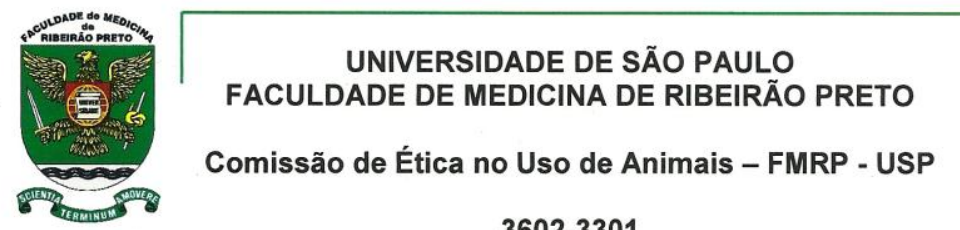

Comissão de Ética no Uso de Animais - FMRP - USP

$3602-3301$

\section{CER TIF I C A D O}

Certificamos que o Protocolo para Uso de Animais em Experimentação $\mathbf{n}^{\mathbf{0}} \mathbf{0 8 6 / 2 0 1 3}$, sobre o projeto intitulado "Efeitos da inibição da via GCs-GMPc pelo azul de metileno na redução do edema pulmonar decorrente da lesão pulmonar aguda induzida por ácido oléico", sob a responsabilidade do Professor Doutor Paulo Roberto Barbosa Evora está de acordo com os Princípios Éticos em Experimentação Animal adotado pelo Conselho Nacional de Controle de Experimentação Animal (CONCEA) e foi APROVADO em reunião de 25 de novembro de 2013.

We certify that the protocol $n^{\circ} 086 / 2013$, entitled "Effects of inhibition of the cGMP by sGC-methylene blue reduction in pulmonary edema resulting from acute lung injury induced by oleic acid", is in accordance with the Ethical Principles in Animal Research adopted by the National Council for the Control of Animal Experimentation (CONCEA) and was approved by the Local Animal Ethical Committee from the School of Medicine of Ribeirão Preto of the University of São Paulo in 11/25/2013.

Ribeirão Preto, 25 de novembro de 2013.

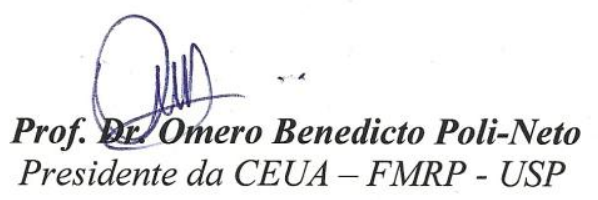

